\title{
Lipid residues preserved in sheltered bedrock features at Gila Cliff Dwellings National Monument, New Mexico
}

\author{
Tammy Buonasera \\ School of Anthropology, University of Arizona, Tucson, U.S.A. Email: tyb@email.arizona.edu
}

\begin{abstract}
:
Bedrock features represent various economic, social, and symbolic aspects of past societies, but have historically received little study, particularly in North America. Fortunately, new techniques for analyzing spatial configurations, use-wear, and organic residues are beginning to unlock more of the interpretive potential of these features. Though preliminary in nature, the present study contributes to this trend by documenting an application of lipid analysis to bedrock features in a dry rockshelter. Results of this initial application indicate that bedrock features in dry rockshelters may provide especially favorable conditions for the preservation and interpretation of ancient organic residues. Abundant lipids, comparable to concentrations present in some pottery sherds, were extracted from a bedrock grinding surface at Gila Cliff Dwellings National Monument and analyzed using gas chromatography-mass spectrometry. Though the lipids were highly oxidized, degradation products indicative of former unsaturated fatty acids were retained. Comparisons to experimentally aged residues, and absence of a known biomarker for maize, indicate that the bulk of the lipids preserved in the milling surface probably derive from processing an oily nut or seed resource, and not from processing maize. Substantially lower amounts of lipids were recovered from a small, blackened cupule. It is hypothesized that some portion of the lipids in the blackened cupule was deposited from condensed smoke of cooking and heating fires in the caves. Potential for the preservation of organic residues in similar sheltered bedrock contexts is discussed, and a practical method for sampling bedrock features in the field is described.
\end{abstract}

Keywords: bedrock features; cupules; ground stone tools; Gila Cliff Dwellings; GC-MS; lipid analysis

\section{Introduction}

For several decades, lipid analysis via gas chromatography-mass spectrometry (GC-MS) has helped identify sources of organic residues absorbed in the fabric of ancient pottery (Condamin et al. 1976; Evershed et al. 1992; Evershed 2008b). More recently, lipid analysis has enjoyed increased use among a wider range of archaeological materials including stone and ceramic pipes (Rafferty 2006; Tushingham et al. 2013), stone cooking vessels (Namdar et al. 2009), coprolites (Sistiaga et al. 2014), and anthropogenic soils and sediments (Bull et al. 1999; Hjulstrom \& Isaksson 2009; Kedrowski et al. 2009; Heron et al. 2010; Birk et al. 2011;

Published by the School of History, Classics and Archaeology, University of Edinburgh ISSN: 2055-0472. URL: http://journals.ed.ac.uk/lithicstudies/

This work is licensed under a Creative Commons Attribution 2.5 UK: Scotland License. 
Buonasera et al. 2015). Despite these and other productive applications, research on lipids preserved in rock surfaces has so far been minimal (Burton 2003; Buonasera 2007; Buonasera 2013a). Here, I discuss a recent study of lipids present in bedrock features at Gila Cliff Dwellings National Monument. These may be the first samples of bedrock features from dry caves to be analyzed for lipid content, as similar applications were not encountered during a literature search. Sampling for this initial application was limited, and was intended to provide preliminary information to see if a larger study might be merited. Results presented here suggest that sheltered bedrock milling features in arid settings could provide especially favorable contexts for the analysis of lipids or other organic residues.

Bedrock features include mortars, grinding surfaces, cupules, incised lines, and polished surfaces. Cupules are small depressions, often less than $5 \mathrm{~cm}$ in diameter, pecked into rock surfaces (Gilreath 2007). They occur in many prehistoric contexts worldwide (Bednarik 2008). As fixed places on the landscape where people invested considerable time and labor processing resources and conducting related activities, bedrock mortars and grinding features are likely to have held a variety of social, economic, and symbolic values to their past users (Jackson 1991). Often, a range of different types of bedrock features are found in close proximity to one another on various boulders and rock outcrops. Long-term use and re-use of certain locations may have resulted in the accumulation of bedrock features whose functions and significance changed and evolved over time.

While many bedrock features were undoubtedly used to process plant and animal foods, a wide range of other functions are also possible and should be considered depending on observable morphological attributes, wear patterns, and contextual information. For example, certain features may have morphological and wear attributes that are more consistent with the processing of fiber, hides, or pigments, than they are with plant food processing (Adams 1988; Dubreuil \& Grosman 2009). Others may have scant physical evidence for use in any sort of processing activities, but might have held various ritual or other symbolic values to past groups of people (e.g., Parkman 1986; Bednarik 2008; Duwe 2011; Rosenberg \& Nadel 2014).

Increased interest and research concerning bedrock features, along with the development and application of a wide range of techniques for the analysis of ground stone tools, is broadening our understanding of past functions - from processing foods, pigments, or other substances, to exploring social and symbolic contexts of formation and use (Eitam 2009; Nadel \& Lengyel 2009; Leftwich 2010: 128-230; Duwe 2011; Dubreuil \& Savage 2013; Rosenberg \& Nadel 2014; Dubreuil et al. 2015; Nadel et al. 2015). The present study suggests that lipid analysis can add to these developments. Gas chromatography-mass spectrometry of lipid extracts can help identify the presence of seed oils, leaf waxes, various plant resins, as well as plant and animal sterols, animal fats, and fish oils. It is also possible to identify some alkaloids using similar methods (Rafferty 2002; Rafferty 2006; Tushingham et al. 2013). When combined with other techniques such as use-wear analysis, starch analysis, and phytolith analysis, lipid analysis could provide stronger and more detailed interpretations of past functions of sheltered bedrock features.

\subsection{Gila Cliff Dwellings National Monument}

Gila Cliff Dwellings National Monument is located approximately 32 miles northwest of Silver City, New Mexico at 1830m (6000ft) elevation (Figure 1). The Cliff Dwellings include remnants of approximately 50 rock and mud structures within a series of six shallow caves situated in a canyon wall above a small spring-fed stream (Anderson et al. 1986: 9; Nordby 2011: 1). Tree-ring data indicate that extant structures were built between A.D. 1283 and 1287. Earlier and less intensive episodes of construction may also have occurred around A.D. 
1240 (Nordby 2011: 4). Analyses of the pottery assemblage and architectural remains, however, suggest that the existing structures were occupied during the late 13th century by people from the Tularosa Mogollon culture for little more than the span of one generationpossibly by several families who migrated from the San Francisco River drainage approximately $60 \mathrm{~km}$ northwest of the Gila Cliff Dwellings (Anderson et al. 1986: 4-6; Nordby 2011: 9).

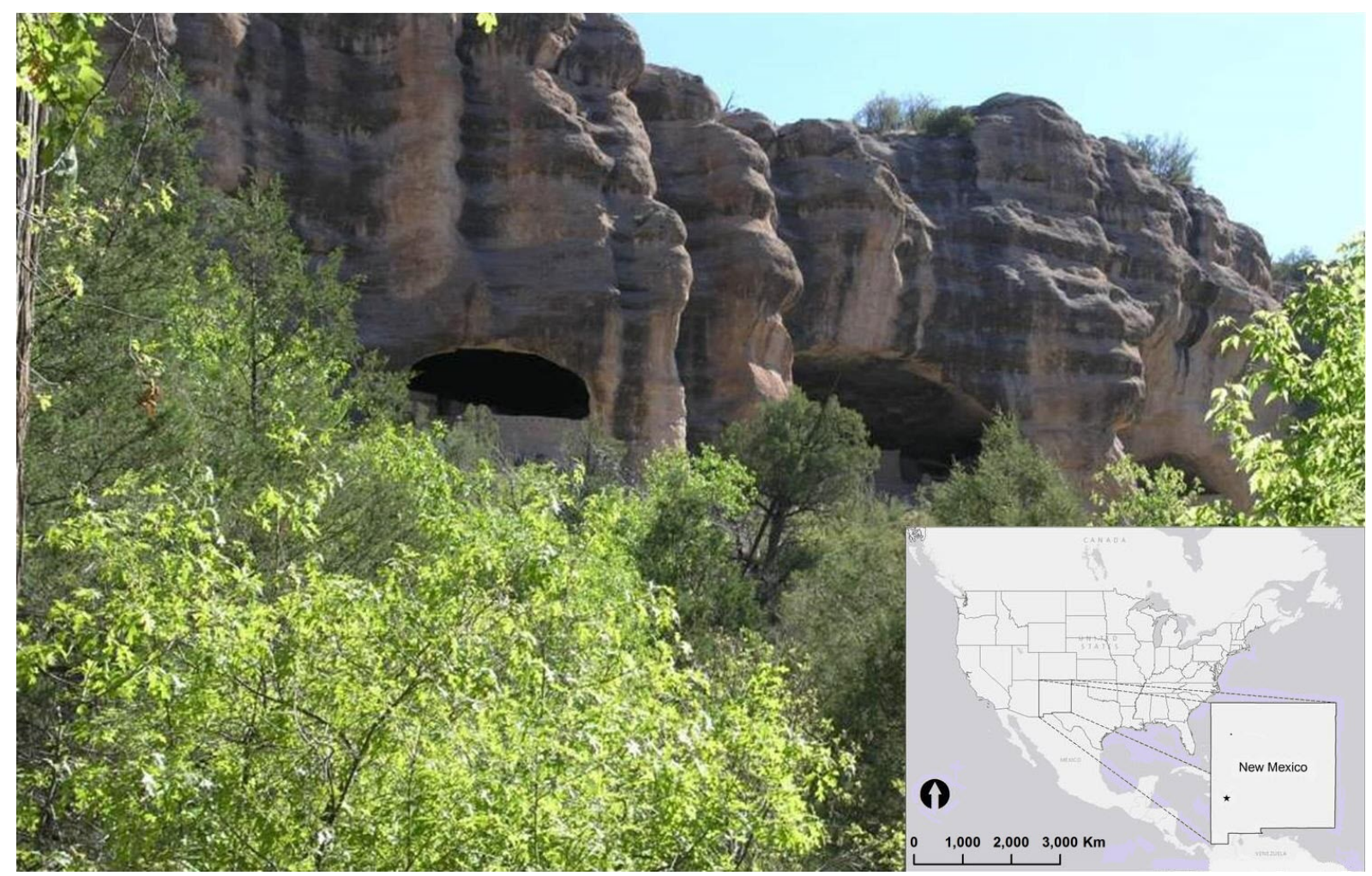

Figure 1. Several of the caves at Gila Cliff Dwellings National Monument, with location map inset. The map was created for this publication by Patrick T. Doyle using ArcGIS software by ESRI. The base layer for the map was obtained through ESRI by ArcGIS Online data access.

Though the architectural remains date to the 13th century, evidence also exists for intermittent use of the caves prior to A.D. 500. Archaic period dart points, a preserved atlatl shaft along with other perishable items, distinctive pictographs and heavy smoke blackening beneath later construction, indicate the caves were used by earlier groups of mobile huntergatherers (Anderson et al. 1986; Nordby 2011). Faunal remains include a range of artiodactyls such as mule deer (Odocoileus hemionus), bison (Bison bison), elk (Cervus canadensis), and pronghorn (Antelocapra americana) (McKusick 1986). Remains of beaver (Castor canedensis) and muskrats (Ondatra zibethicus) are also represented, and may indicate that more mesic conditions once existed at the site.

A wide variety of birds, including feathers and crania of two types of parrots, a thickbilled parrot (Rhynchopsitta pachyrhyncha), and a scarlet macaw (Ara macao), species native to Northern Mexico and Mesoamerica, were recovered as well (McKusick 1986). Floral remains include domesticates such as maize (Zea mays), several types of beans (Phaseolus spp.), and cucurbits in addition to many wild species such as pinyon seeds (Pinus edulis), acorns (Quercus spp.), and wild grass seeds (e.g., Oryzopsis hymenoides) (Adams \& Huckell 1986). Several jimson weed (Datura meteloides) seeds were also encountered in the deposits at Gila Cliff Dwellings (Adams \& Huckell 1986). 
Unfortunately, 19th and early 20th century looting, combined with poor record keeping from early and extensive excavations, have destroyed or diminished much of the material record. The absence of provenience for most artifacts, and uncertain chronological associations for the faunal and floral remains, makes it difficult to determine the nature or extent of earlier uses of the caves, or to evaluate changes in the use of animals and nondomesticated plant resources over time (Anderson et al. 1986). One recent study has focused on recording and interpreting the intact architectural features at Gila Cliff Dwellings (Nordby 2011). However, the many bedrock features present in the caves have so far received little study. These include hundreds of cupules and several mortars and grinding surfaces (Figure 2) that have been pecked and ground into boulders and bedrock surfaces. The past functions and associated dates for these features remain largely unknown.

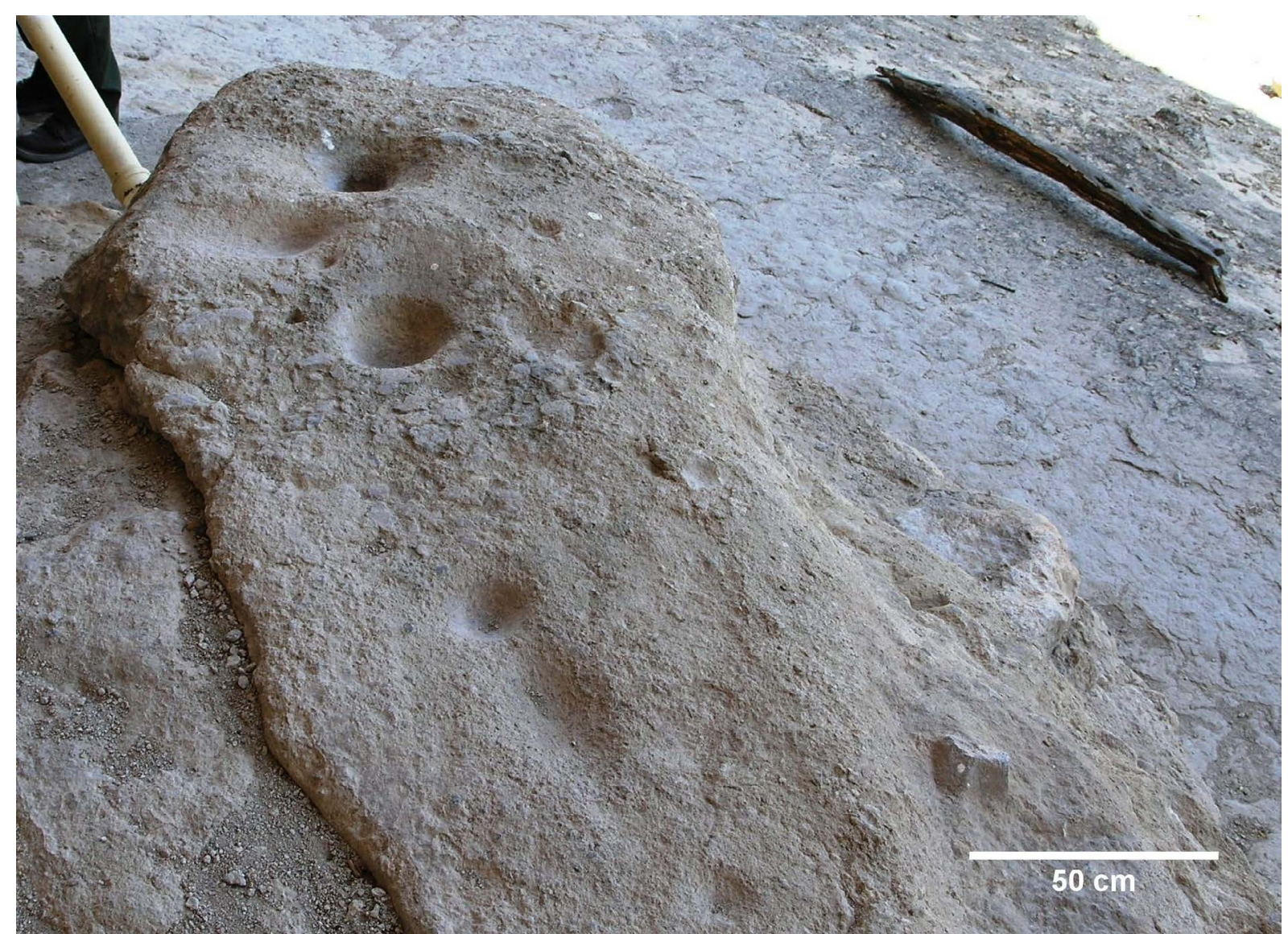

Figure 2. RMP-33 at Gila Cliff Dwellings National Monument, a sheltered bedrock outcrop with several mortars and grinding surfaces. Scale is approximate.

Mortars and grinding surfaces are distinguished from cupules by the shapes and sizes of depressions, as well as patterns of use-wear that may be associated with these features. Mortars are defined here as shallow (5 cm or less) or deeper circular to slightly ovoid depressions that are more than $5 \mathrm{~cm}$ in diameter. Mortar depressions are large enough to contain an intermediary substance as it is pulverized with a pestle. Grinding surfaces are broad and shallow and may be oblong or irregular in outline. Importantly, both mortars and grinding surfaces have wear patterns that indicate they were used to pulverize or grind an intermediary substance.

Cupules are defined as small human-made depressions manufactured in rock surfaces and are generally less than $5 \mathrm{~cm}$ in diameter. Due to their diminutive size, frequent placement on inclined or vertical surfaces, and dense clustering, cupules are usually not interpreted as 
features that played a prominent role in food processing (Parkman 1986; Gilreath 2007; Bednarik 2008). Absence of use-wear can lend further support that cupules were not used to process foods. Furthermore, a number of ethnographic accounts lend credence to the idea that many cupules may have been primarily symbolic or ritual in nature (Parkman 1986; Gilreath 2007; Bednarik 2008). At Gila Cliff Dwellings, some cupules occur on horizontal surfaces (Figure 3), while others are located on steeply inclined or vertical surfaces (Figure 4). Many are covered with layered deposits of unknown origin (Figure 5). Though we do not know when the cupules were manufactured, some must pre-date the $13^{\text {th }}$ century Mogollon construction sequence as walls have been built directly over portions of several cupule panels (see Figures 3 and 4).

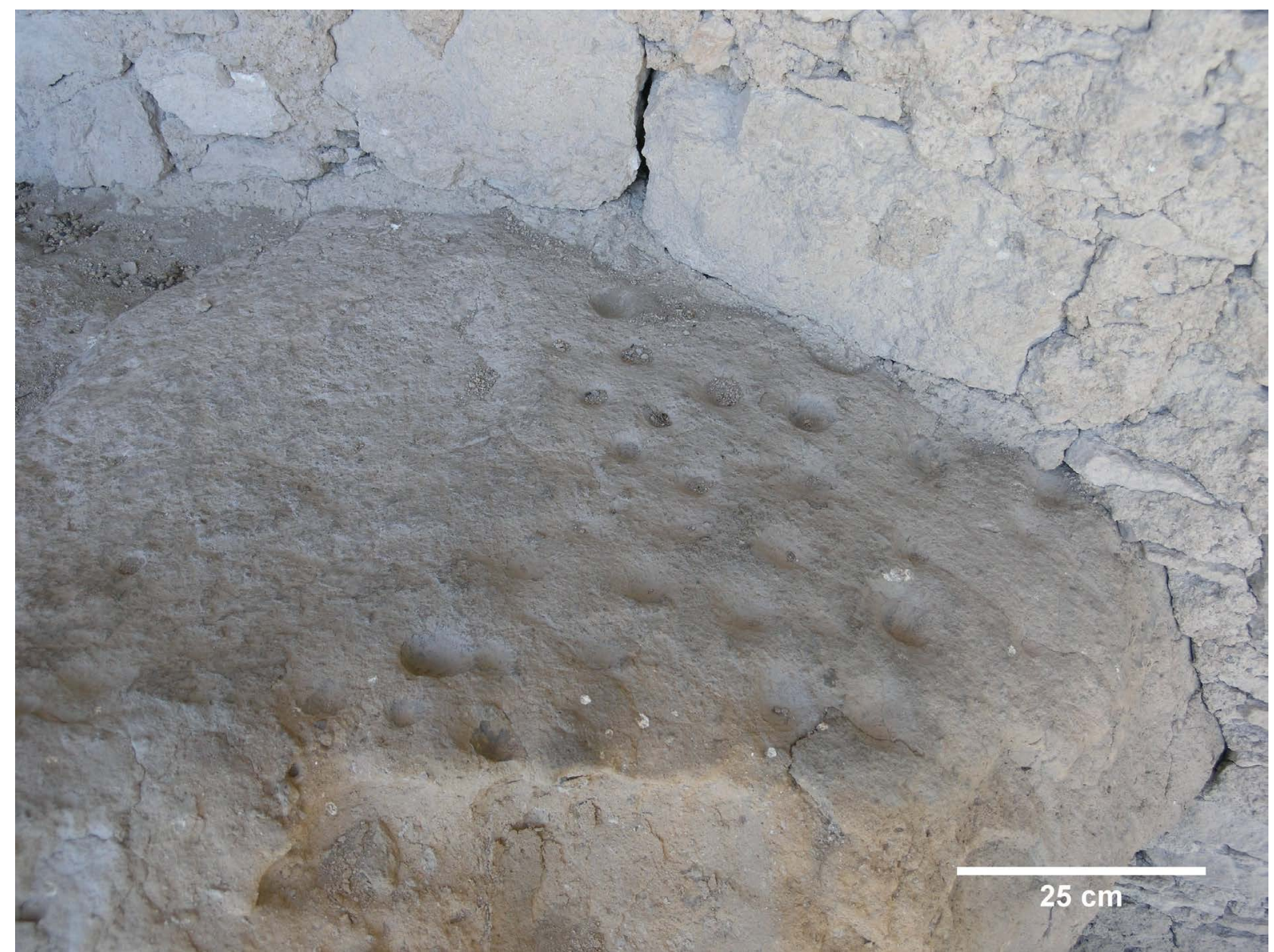

Figure 3. RMP-5 at Gila Cliff Dwellings National Monument with cupule depressions. Scale is approximate.

Lipid analysis was applied to see if it could provide information on what types of substances, if any, were processed in, or associated with, different bedrock features at Gila Cliff Dwellings. The following study analysed solvent extractable lipids present in a cupule, a grinding feature, a dark layered deposit, and a white deposit present on boulders in the dry caves at Gila Cliff Dwellings. Lipid concentrations extracted from the cupule and the grinding surface samples were compared with amounts extracted from unused surfaces of their respective boulders. The unused surfaces provided negative controls against lipid content that may have been introduced through human uses, such as food processing or preparation of ritual substances. The overall lipid profile including fatty acids, alkanes, and a range of degradation products, was analysed to explore the general character of solvent extractable residues and to suggest potential sources. 


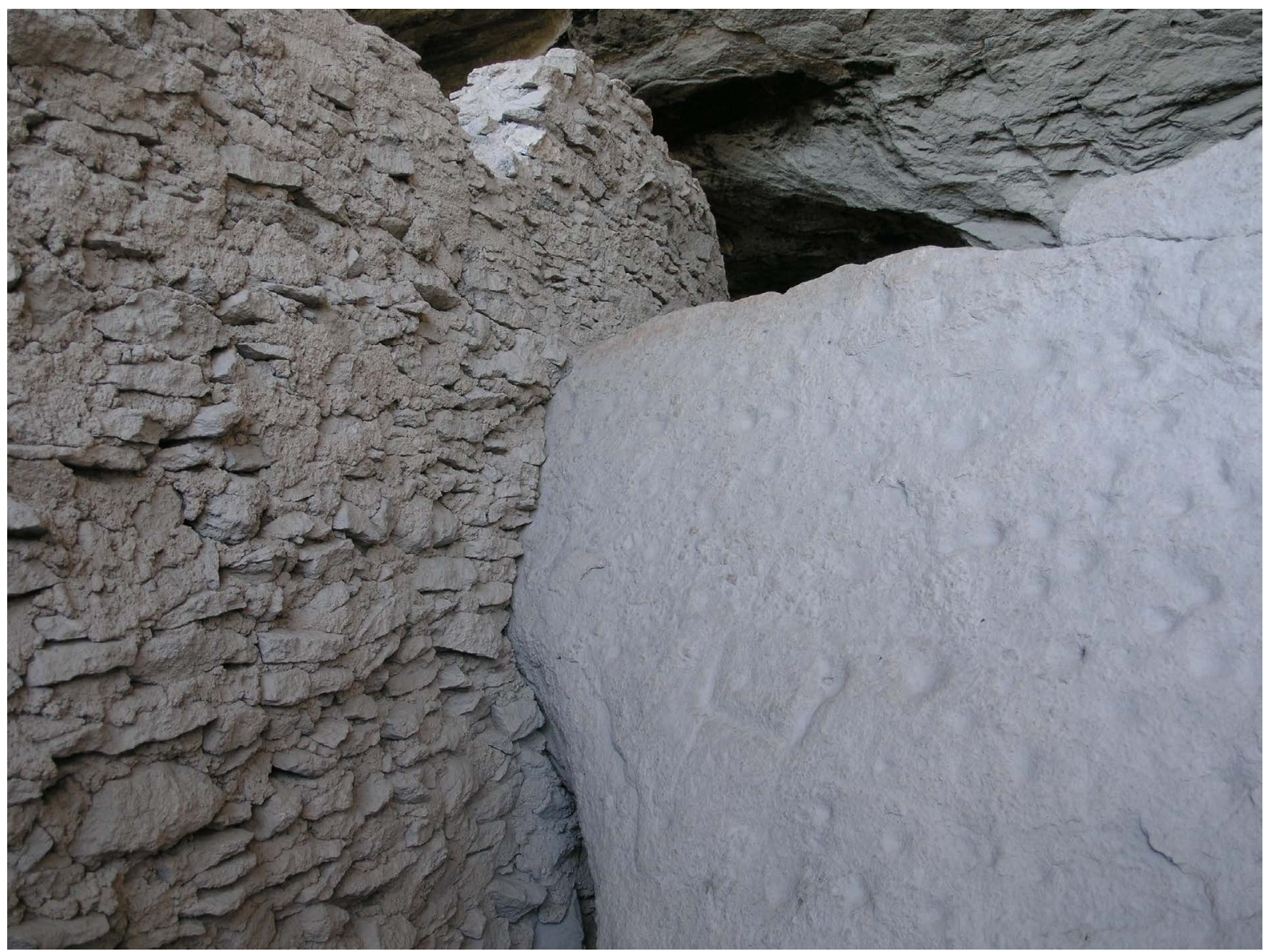

Figure 4. Exterior of the northeast wall of room 27 built over the west end of a vertical cupule panel on the south side of RMP-4. The cupule panel is a little more than $2 \mathrm{~m}$ in height.

\subsection{Lipid analysis of ground stone tools}

Lipid analysis via GC/MS has been applied to archaeological pottery since the 1970's. Over the past two decades, advances have been made in the use of biomarker compounds and stable $\delta 13 \mathrm{C}$ analysis enabling differentiation of aquatic fats, ruminant adipose fats, milk fats, and maize in archaeological ceramics (Dudd \& Evershed 1998; Copley et al. 2003; Hansel et al. 2004; Reber et al. 2004; Craig et al. 2007). Applications to ground stone tools, however, have been few and identification of source materials has been less specific (Burton 2003; Buonasera 2007). Several reasons can be proposed to account for this situation. To begin, even a cursory glance of the literature will reveal far fewer studies devoted to ground stone tools than to archaeological ceramics. Also, researchers may be reluctant to apply lipid analysis to ground stone tools because the preservation potential of lipids in most rock surfaces is likely to be less favorable than it is for low-fired ceramics. Low-fired pottery has a favorable porosity profile and more potential sites for molecular interactions between minerals and organic matter than many rock surfaces (Craig \& Collins 2002; Craig et al. 2004; Evershed 2008a; Namdar et al. 2009). Finally, with the exception of maize, identification of different types of plant oils has remained elusive do to a lack of known lipid biomarkers for important resources such as C3 grass seeds, nuts, or acorns—staple plant foods often associated with ground stone milling tools. 


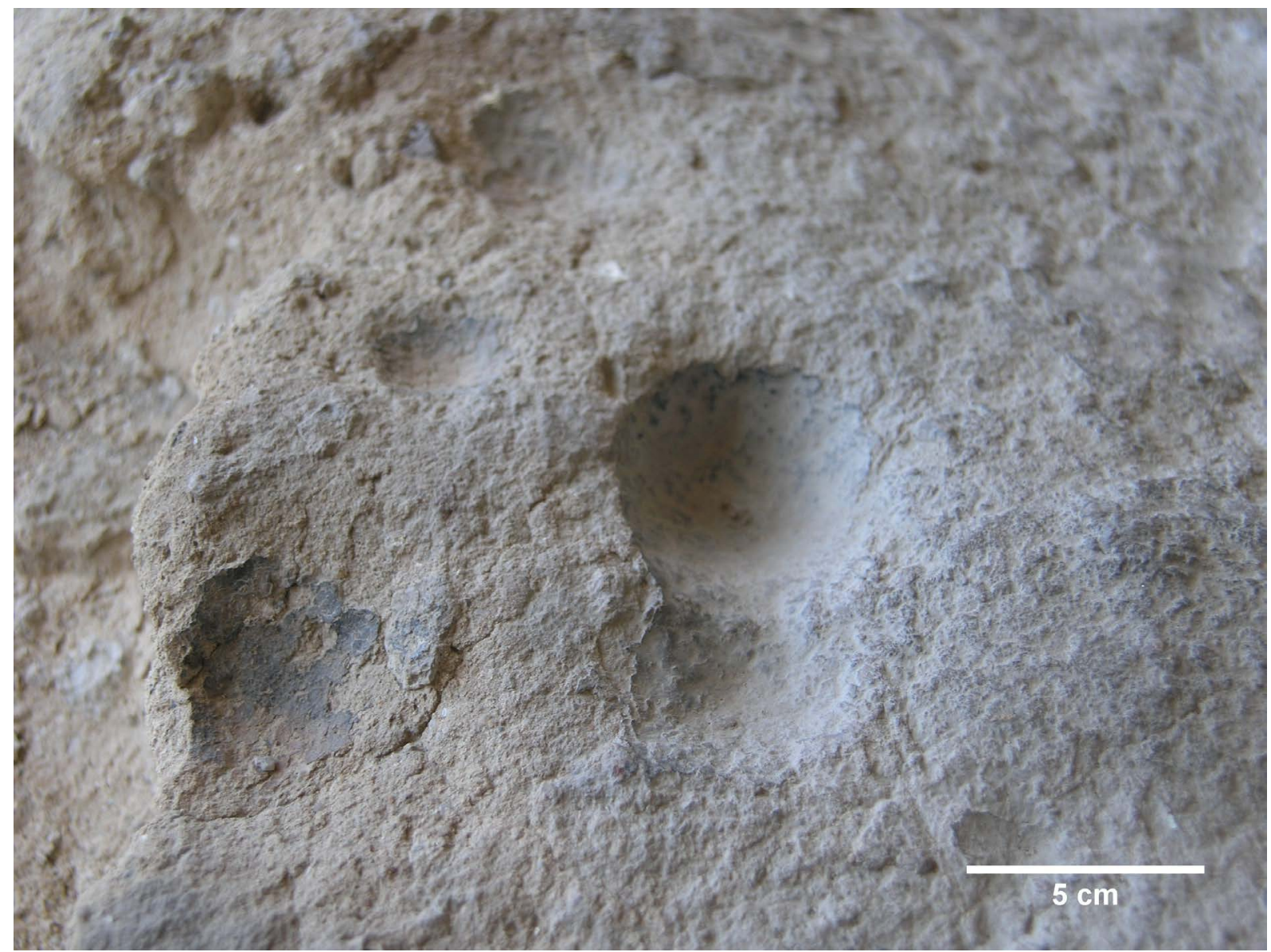

Figure 5. Blackened surface residues in RMP-5 cupules. Scale is approximate.

Despite these challenges, preservation of lipids has been demonstrated in some archaeological ground stone tools and additional, more focused, studies could help to improve the specificity of plant food identifications. In considering future applications, the presence and preservation of ancient lipids in ground stone tools should be affected by: 1) past uses; 2) the porosity and mineral composition of the rock matrix; and 3) the post-depositional environment. First, certain resources such as seeds, nuts, fish oil, or milk fat are very fatty or oily, while others like roots or legumes have much lower amounts of lipids. Lower amounts of lipids are less likely to be absorbed, survive over time, and produce a distinct signal. Second, the porosity of rocks matrices can vary widely, and the porosity profile of some types of rocks are probably more or less amenable for retaining organic residues (Namdar et al. 2009). Third, like other organics, lipids are better preserved in very cold, anaerobic, or very dry, sheltered settings (Morgan et al. 1984; Evershed 2008a; Buonasera 2013a; Buonasera et al. 2015).

For this last reason, bedrock milling features that are protected within dry rockshelters could provide especially favorable contexts for lipid preservation. In addition to lipids, bedrock features may also retain more water-soluble organic compounds like phenolics or alkaloids, as there is less exposure to water moving through the depositional matrix than among materials found in open sites. The bedrock features sampled at Gila Cliff Dwellings are protected inside the dripline of the caves. In addition, highly perishable items including mummified human remains, feathers, wooden beams, baskets, and sandals have been recovered from Gila Cliff Dwellings (Anderson et al. 1986). 


\section{Methods}

\subsection{Sampling}

Six samples were selected and collected on May 22, 2010 by the author and National Park Service Ranger, Kara Naber (permit no. 10-GICL-01). Descriptions of samples are provided in Table 1. Samples from two visible surface deposits were collected, and four rock samples were removed from the upper 1-2 cm of two boulders with cupules or other modifications (RMP-5 and RMP-33). Boulders and bedrock surfaces with cupules or other modifications have designated Rock Modification Panel (RMP) numbers following Nordby (2011). A dark, layered deposit (one of the two sampled visible deposits) covering the surface of a cupule on RMP-5 can be seen in Figure 5. A white deposit on portions of the east end of RMP-4 was also sampled (not shown). Small rock cores (approximately $1.5 \mathrm{~cm}$ in diameter by $1 \mathrm{~cm}$ deep) were removed using solvent cleaned diamond-embedded core drill bits and a portable electric drill. Small rock cores were removed from a cupule on RMP-5 (Figure 6) and from a grinding surface at the edge of one mortar on RMP-33 (Figure 7). Control samples of rock surfaces were broken off portions of the corresponding RMPs where no use-wear or layered coating was evident. Nitrile gloves were worn during sampling, and all samples were immediately wrapped in aluminum foil and placed in plastic bags until analyzed by the author at the Institute for Integrated Research in Materials, Environment and Society (IIRMES) at California State University, Long Beach during October 2010.

Table 1. Quantities of FAMEs in Gila Cliff Dwellings samples. Abbreviation: FAME: fatty acid methyl esters. Abbreviations: N/A - Not applicable

\begin{tabular}{|c|c|c|c|c|}
\hline Sample & Sample description & Geology & $\begin{array}{c}\text { Sample } \\
\text { wt. (g) }\end{array}$ & $\begin{array}{c}\text { Total } \\
\text { FAME } \\
\text { ( } \mu \mathrm{g} g-1)\end{array}$ \\
\hline GNM 1-1 & $\begin{array}{l}\text { Layered black deposit in RMP-5 cupule, } \\
\text { flaked-off piece of deposit }\end{array}$ & N/A & 0.137 & 2.53 \\
\hline GNM 1-2 & $\begin{array}{l}\text { Blackened cupule bottom, RMP-5, drilled } \\
\text { core }\end{array}$ & $\begin{array}{c}\text { Gila } \\
\text { Conglomerate }\end{array}$ & 0.496 & 33.15 \\
\hline GNM 1-3 & $\begin{array}{l}\text { Control-unmodified portion of RMP-5, } \\
\text { piece of rock surface }\end{array}$ & $\begin{array}{l}\text { Gila } \\
\text { Conglomerate }\end{array}$ & 0.964 & 4.46 \\
\hline GNM 3-1 & Grinding surface, RMP-33, drilled core & $\begin{array}{c}\text { Gila } \\
\text { Conglomerate }\end{array}$ & 0.879 & 278.23 \\
\hline GNM 3-2 & $\begin{array}{l}\text { Control- unmodified portion of RMP-33, } \\
\text { piece of rock surface }\end{array}$ & $\begin{array}{l}\text { Gila } \\
\text { Conglomerate }\end{array}$ & 1.468 & 3.27 \\
\hline GNM 2-1 & White deposit from RMP-4, surface scrape & $\mathrm{N} / \mathrm{A}$ & 0.367 & 0.38 \\
\hline
\end{tabular}

\subsection{Laboratory methods and interpretation}

In the lab, samples were ground to a fine powder using a solvent-cleaned laboratory mortar and pestle, and then extracted with organic solvents. Lipid extracts were derivatized to methyl esters to increase the volatility of fatty acids prior to GC/MS analysis. Additional details on extraction and derivatization follow. Each ground sample was extracted in $15 \mathrm{ml}$ of a single phase CMW mixture (chloroform: methanol: water; $\mathrm{v} / \mathrm{v}, 1: 2: 0.8)$ with sonication $(2 \mathrm{x}$ $15 \mathrm{~min})$. Extracts were centrifuged and the supernatant removed to a fresh tube. Pelleted sediments were rinsed with $5 \mathrm{ml} \mathrm{CMC}$, re-centrifuged, and supernatants combined. Next, one part water and one part chloroform were added to the CMW extract, resulting in a lower chloroform phase containing neutral lipids and an upper water-methanol phase containing compounds that are more polar. This step removes less-volatile impurities from the lipid extract. The neutral lipid containing chloroform phase was removed to a clean test tube using 
Pasteur pipettes and the water-methanol phase rinsed with $2 \mathrm{ml}$ chloroform (2X). The lipid extract was dried under a gentle stream of nitrogen and derivatized to methyl esters by adding $3 \mathrm{ml}$ of dry $\mathrm{HCl}$ in methanol $(1.25 \mathrm{M})$ and heating at $60{ }^{\circ} \mathrm{C}$ for 90 minutes. The reaction was quenched with a saturated sodium bicarbonate solution and derivatized lipids were extracted with $2 \mathrm{~mL}$ hexane (3X) and dried under nitrogen. Dried lipids were raised in $100 \mu \mathrm{l}$ chloroform, tightly capped, and stored in amber vials at $-70^{\circ} \mathrm{C}$.

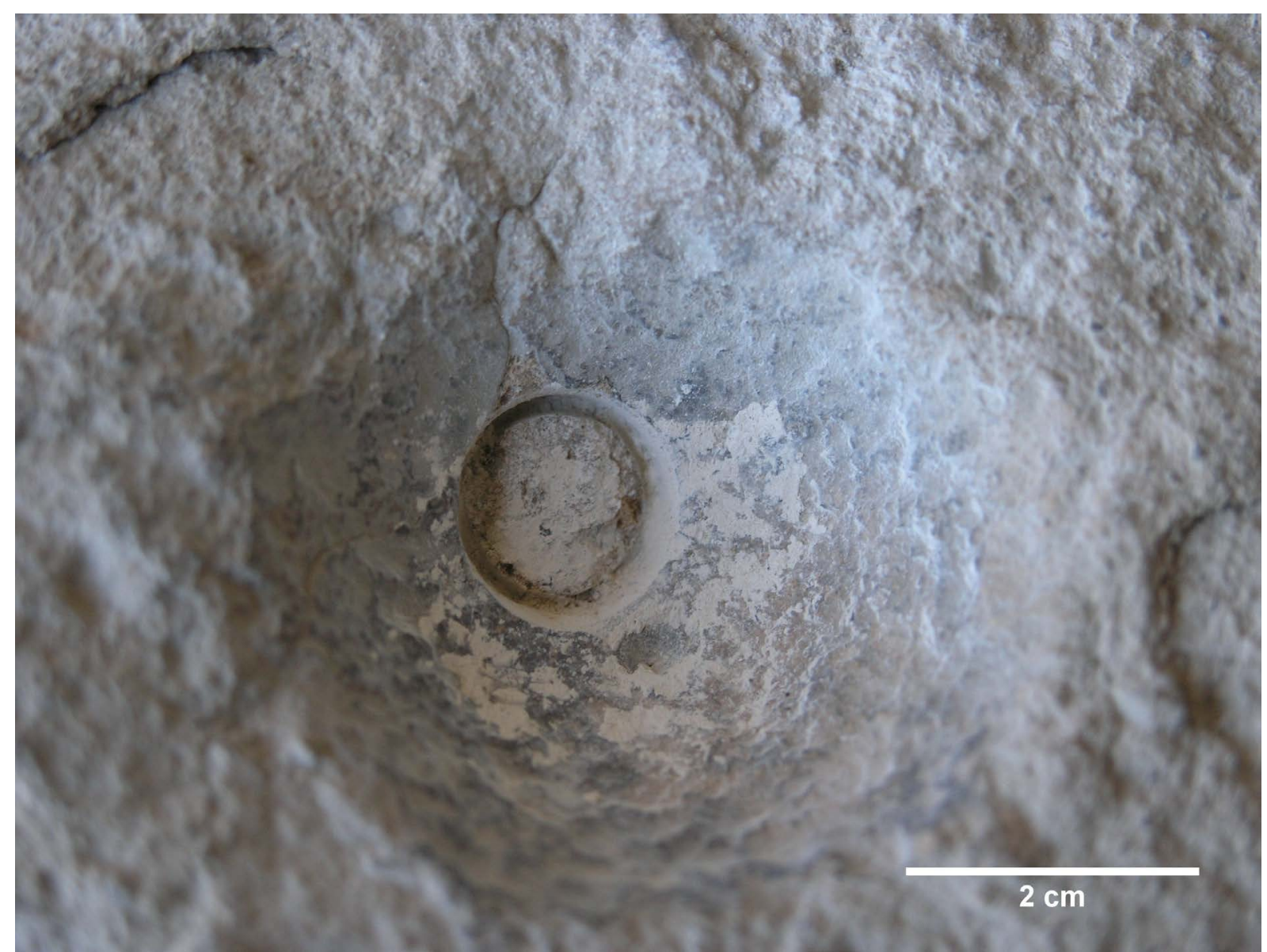

Figure 6. Sampled RMP-5 cupule. Scale is approximate.

Care was taken throughout to guard against potential sources of contamination. Nitrile gloves were worn during all phases of sample handling and preparation. Glassware was washed with an alkaline laboratory cleanser, baked at $500{ }^{\circ} \mathrm{C}$ in a kiln, and solvent rinsed to remove organics prior to use. In addition, a sample blank was processed along with each batch of samples to detect potential contaminants present in solvents or introduced through other laboratory sources.

A known amount of internal standard (C19:0, Restek) was placed in sample GMN 3-2. The response (measured in area counts) from this was used to calculate fatty acid quantities (as FAMES - fatty acid methyl esters) in all samples. Internal standard (IS) was not added to all of the samples, as the potential range of lipids in the samples was unknown. Fortunately, the IS in GMN 3-2 was in an appropriate range and is applicable to all of the samples as they were each run on the same column, on the same day, under the same conditions.

Lipid extracts were analysed on an Agilent 6890 GC coupled to a HP 5973 MSD (EI, 70 $\mathrm{eV}$ ). A $2 \mu \mathrm{L}$ aliquot of each derivatized sample extract was injected (splitless) onto a DB-5 column (60 m x $0.25 \mathrm{~mm}$ i.d.). After a 5 minute hold at $45^{\circ} \mathrm{C}$, column temperature was ramped to $150^{\circ} \mathrm{C}$ at $25^{\circ} \mathrm{C}$ per minute, then to $285^{\circ} \mathrm{C}$ at $2.5^{\circ} \mathrm{C}$ per minute with a 16.8 minute 
hold at $285^{\circ} \mathrm{C}$. Inlet temperature was held at $285^{\circ}$. Peaks were integrated and analysed with the aid of HP Chemstation software. Identifications were based on comparison to the NIST mass spectral search program 2.0 and by comparison to retention times (RT) and mass spectra of known fatty acid standards (SP-37, Supelco).

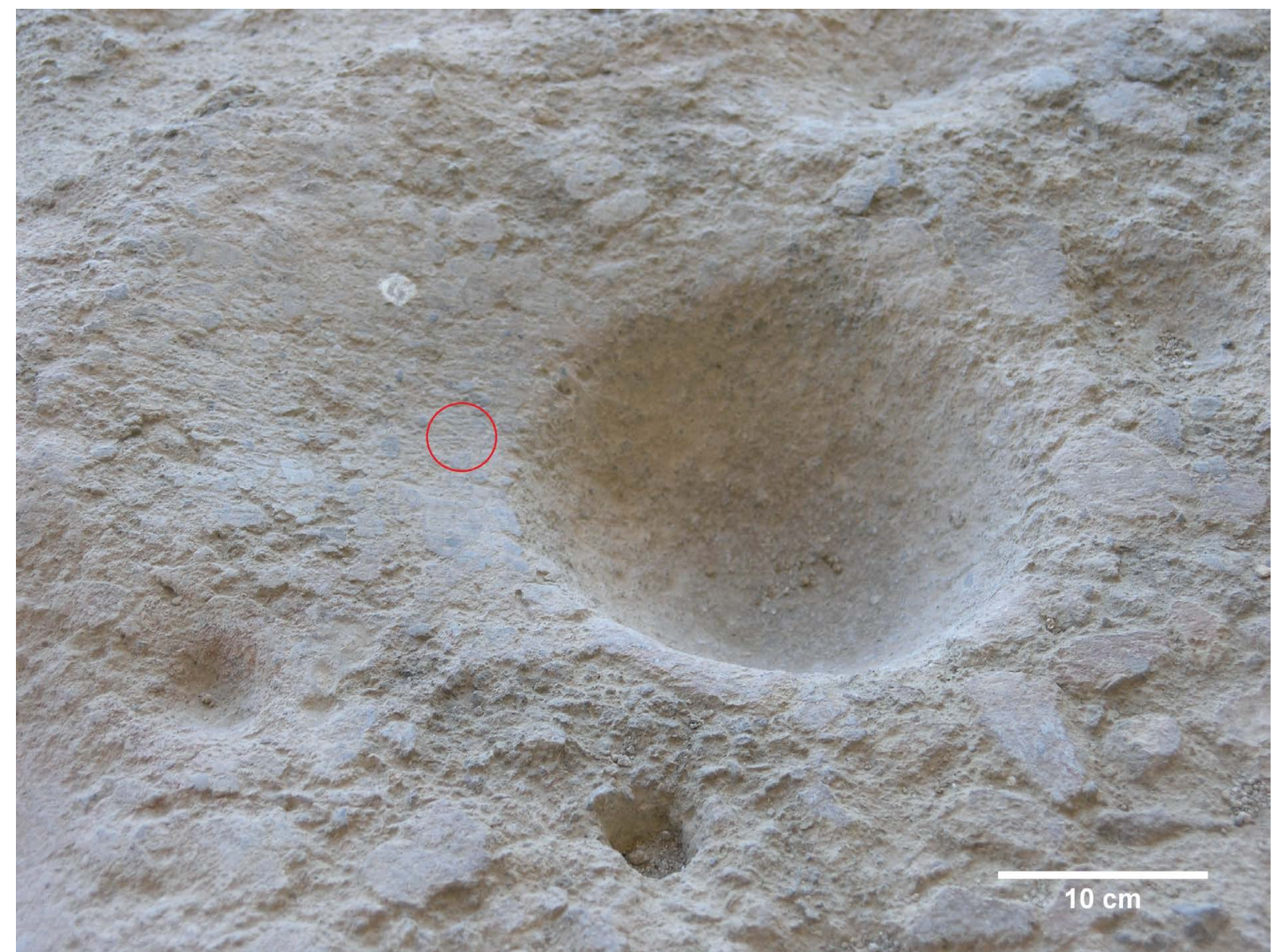

Figure 7. Grinding surface adjacent to mortar depression on RMP-33, the red circle indicates the location of sample 3-1. Scale is approximate.

Samples from modified and unmodified portions of the same boulders (RMP-5 and RMP33) were compared. Samples from features that were used to process plant or animal resources in the past were expected to have significantly higher quantities of fatty acids than unused portions of the same rock. Overall, the identification of anthropogenically introduced lipids and tentative source identifications discussed in the following section are based on: 1) fatty acid concentrations present in the samples and controls, 2) ratios of two pairs of common saturated fatty acids, and, 3) the presence of other lipid compounds including alkanes, hydroxy and dihydroxy fatty acids, dicarboxylic fatty acids, and long chain fatty acids.

\section{Results and discussion}

\subsection{Lipid quantities}

The two samples of visible surface residues did not contain any interpretable lipids. Both of these samples had very low quantities of lipids $\left(<2 \mu \mathrm{g} \mathrm{g}^{-1}\right)$ with only small amounts of fatty acids C16:0 and C18:0 detected. Table 1 lists the concentration of fatty acids recovered from all samples, including the two core samples and their corresponding controls. Figures 8 and 9 are the total ion count chromatograms (TICs) for the core samples and their corresponding 
controls. Control samples of rock surfaces from RMP-5 and RMP-33 also had low concentrations of fatty acids $\left(<5 \mu \mathrm{g} \mathrm{g}^{-1}\right)$. The core sample from the cupule on RMP-5 had a fatty acid concentration of $33 \mu \mathrm{g} \mathrm{g}^{-1}$; approximately seven times greater than the amount detected in the corresponding control sample. Significantly, the core sample taken from the grinding surface on RMP-33 had $278 \mu \mathrm{g} \mathrm{g}^{-1}$ of fatty acids (and about $353 \mu \mathrm{g} \mathrm{g}^{-1}$ of total extractable lipids), approximately 85 times the fatty acid concentration detected in the corresponding control sample. It is worth noting that this appreciable concentration of fatty acids is in the range of those recovered from pottery sherds that have been used to directly date the use of some pottery vessels (Stott et al. 2001; Stott et al. 2003; Berstan et al. 2008). The minimum acceptable lipid concentration in sherds dated by Stott et al. (2001: 192) was $300 \mu \mathrm{g}$ of total extractable lipid per gram of powdered sherd. For Berstan et al. (2008: 710) the cut-off in lipid concentration was a little higher, around 500 $\mathrm{g} \mathrm{g}^{-1}$.

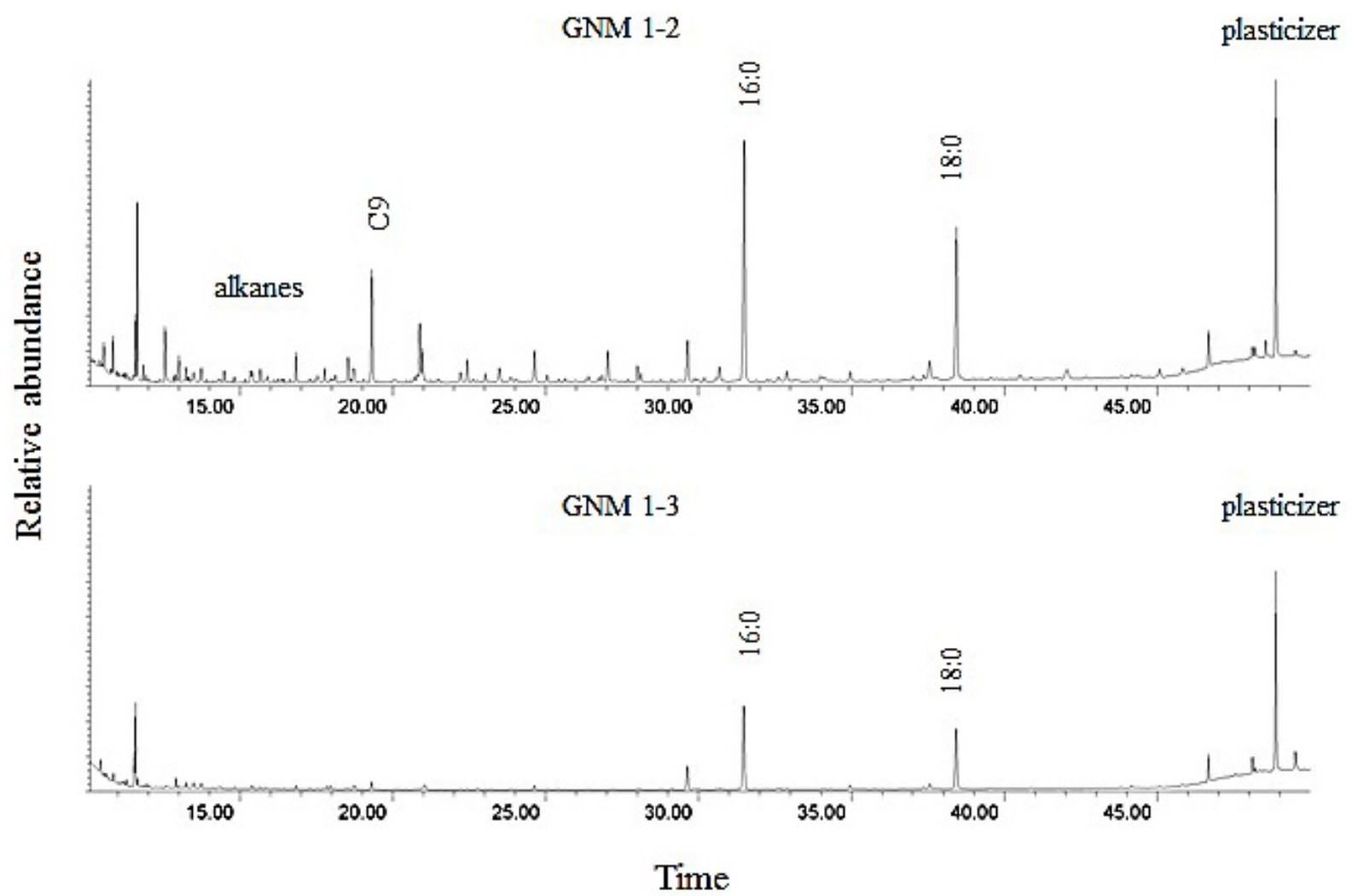

Figure 8. Partial total ion chromatograms for the cupule core (upper TIC) and control sample (lower TIC) from RMP-5. Peaks in the upper and lower TICs are plotted to the same scale.

Because the residue from the grinding surface sample had approximately 85 times the amount of lipid as the rock sample from an unmodified portion of the same boulder's surface, it is assumed that potential contributions from environmental lipids are low enough to not significantly affect the overall lipid profile or ratios of common saturated fatty acids used for identification. This is important because it is possible that some portion of the lipids detected in samples from Gila Cliff Dwellings originate from past cooking or heating fires within the cave. The solvent soluble portion of wood smoke contains various hydrocarbons including alkanes and fatty acids, various substituted monocyclic aromatic compounds, polycyclic aromatic hydrocarbons (PAHs), and terpenoid resins (Standley \& Simoneit 1987; Simoneit et al. 2000; Naeher et al. 2007). The possibility that wood smoke contributed to the formation of some deposits in the cave was also mentioned in a prior study (Lambert 1990). In the present study, it seems notable that each of the rock samples contained similar concentrations of 
alkanes even though some samples had much higher concentrations of fatty acids. As a result, ratios of alkanes to fatty acids are variable. In fact, the amount of fatty acids in the grinding surface sample is several orders of magnitude greater than the alkanes, which makes the ratio of alkanes to fatty acids in this sample appear as zero in Table 2.

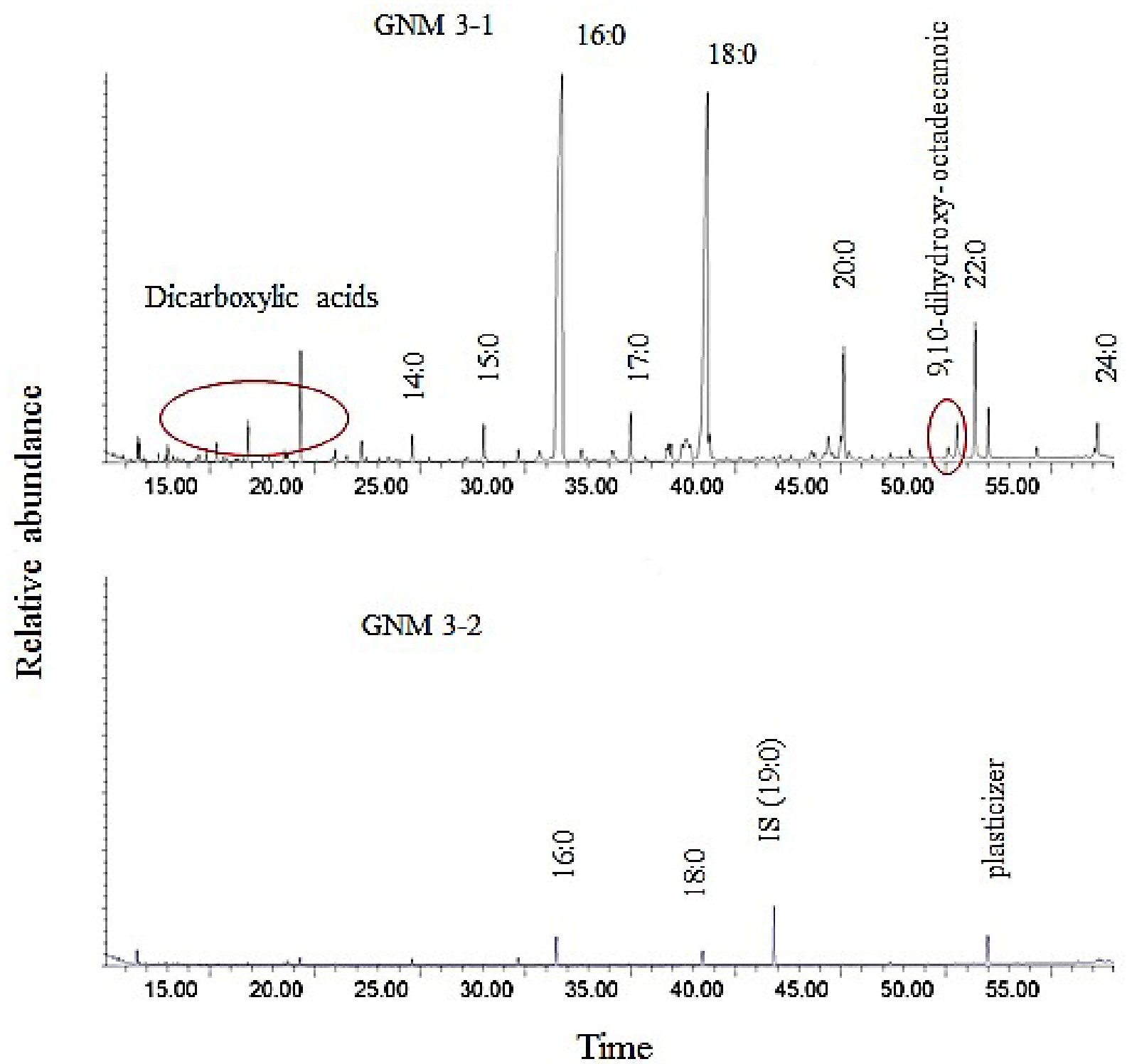

Figure 9. Partial total ion chromatograms for the grinding surface core (upper TIC) and control sample (lower TIC) from RMP-33. Peaks in the upper and lower TICs are plotted to the same scale.

\subsection{Qualitative comparisons of lipid content in the grinding surface}

Saturated fatty acid ratios and the presence of other diagnostic lipids are listed in Table 2, while relative percentages of major fatty acids are shown in Table 3. Lipids in the grinding surface appear to be highly oxidized. Given the relatively high concentrations of fatty acids in this sample, a complete lack of oleic acid (C18:1n9), or other monounsaturated fatty acids, together with a relatively high amount of $\alpha$, $\omega$-dicarboxylic acids (often referred to as diacids), indicates the highly oxidized condition of the residue. Ratios of saturated fatty acids C12:0/C14:0 and C16:0/C18:0 are consistent with values obtained for experimentally aged plant or, seed residues (Eerkens 2005; Buonasera 2013a). The suite of diacids in this residue, ranging from $\mathrm{C} 7$ to $\mathrm{C} 12$, with $\mathrm{C} 9$ (azelaic acid) dominating, indicates the residue once contained abundant quantities of C18:1n9 as well as polyunsaturated fatty acids (Passi et al. 
1993; Regert et al. 1998). Autoxidation of the double carbon bond in C18:1n9 produces C9 as the dominant diacid. This is related to the position of the double bond between carbons 9 and 10. Polyunsaturated fatty acids tend to produce a dominant diacid reflecting the position of the first double bond, and a secondary diacid with two fewer carbons (Passi et al. 1993: 195).

Table 2. Saturated fatty acid ratios and other lipids. Abbreviations: unid: unidentified

\begin{tabular}{|c|c|c|c|c|c|c|}
\hline Sample & $\begin{array}{c}\text { C12:0/ } \\
\text { C14:0 }\end{array}$ & $\begin{array}{c}\text { C16:0/ } \\
\text { C18:0 }\end{array}$ & $\begin{array}{c}\text { Ratio } \\
\text { ID }^{\mathrm{b}}\end{array}$ & $\begin{array}{l}\text { Ratio of } \\
\text { alkanes } \\
\text { to FA }\end{array}$ & Other lipids & Interpretation \\
\hline $\begin{array}{l}\text { GNM 1-2 } \\
\text { Cupule }\end{array}$ & 0.50 & 1.65 & plant & 0.15 & $\begin{array}{l}\text { Complex array of } \\
\text { monocyclic } \\
\text { aromatic } \\
\text { hydrocarbons }\end{array}$ & $\begin{array}{l}\text { Accumulation of } \\
\text { lipids possibly from } \\
\text { wood smoke and } \\
\text { another plant source }\end{array}$ \\
\hline $\begin{array}{l}\text { GNM 1-3 } \\
\text { Control for } \\
\text { cupule }\end{array}$ & 0.00 & 1.34 & unid & 0.50 & & $\begin{array}{l}\text { Natural background } \\
\text { lipids with possible } \\
\text { contribution from } \\
\text { wood smoke }\end{array}$ \\
\hline $\begin{array}{l}\text { GNM 3-1 } \\
\text { Grinding } \\
\text { surface }\end{array}$ & 0.33 & 1.36 & plant & 0.00 & $\begin{array}{l}\text { Two 9,10-dihydroxy- } \\
\text { octadecanoic acid } \\
\text { isomers, hydroxy- } \\
\text { fatty acids, } \alpha, \omega- \\
\text { dicarboxylic acids }\end{array}$ & $\begin{array}{l}\text { Oily seed or nut, } \\
\text { possibly exposed to } \\
\text { heat during } \\
\text { processing }\end{array}$ \\
\hline $\begin{array}{l}\text { GNM 3-2 } \\
\text { Control for } \\
\text { grinding } \\
\text { surface }\end{array}$ & 0.63 & 2.02 & plant & 0.23 & & $\begin{array}{l}\text { Natural background } \\
\text { lipids with possible } \\
\text { contribution from } \\
\text { wood smoke }\end{array}$ \\
\hline $\begin{array}{l}\text { Aged } \\
\text { sunflower } \\
\text { seed residue }^{a}\end{array}$ & 0.80 & 1.73 & plant & 0.00 & $\begin{array}{l}\text { 9,10-dihydroxy- } \\
\text { octadecanoic acid, } \\
\text { hydroxy-fatty acids, } \\
\alpha, \omega \text {-dicarboxylic } \\
\text { acids }\end{array}$ & $\begin{array}{l}\text { Degraded, highly } \\
\text { oxidized, sunflower } \\
\text { seed lipids }\end{array}$ \\
\hline
\end{tabular}

Notes:

a. From an upper grinding stone used to grind commercial sunflower seeds approximately 20 years ago (Buonasera 2013a).

b. Based on saturated fatty acid ratios in Eerkens (2005: Table 2)

In addition to diacids, hydroxy acids are known to form during oxidation and heating (Regert et al. 1998; Hansel \& Evershed 2009). Hydroxy acids 16 and 18 carbons long, and a mixture of two 9, 10-dihydroxy-octadecanoic acid isomers are also present. Several studies have shown that erythro and threo isomers of 9,10-dihydroxy-octadecanoic acid form during thermal degradation and oxidation of oleic acid (Regert et al. 1998; Hansel \& Evershed 2009). The diacid and dihydroxy products in this residue are consistent with a source that once contained high amounts of unsaturated fatty acids such as oleic acid (C18:1n9), linoleic acid (C18:2), or linolenic acid (C18:3) (Passi et al. 1993; Hansel \& Evershed 2009). Many fresh seed oils contain high amounts of C18:2 and C18:3 in addition to C18:1n9. Furthermore, this residue contained C20:0 and several very long chain fatty acids from 22 to 25 carbons in length. Very long chain saturated fatty acids are found in some seed oils, and are components of plant waxes, but are uncommon in terrestrial animal fats (Gunstone 1999; Regert 2011).

The presence of two 9,10-dihydroxy-octadecanoic acid isomers in this archaeological residue is made more interesting by their absence in highly oxidized residues from aged experimental grinding tools (Buonasera 2013a). Patterns of lipid oxidation in experimental 
sandstone upper grinding stones were described in a previous study (Buonasera 2013a). In that study, each experimental upper grinding stone had been used approximately 20 years ago to process a unique substance-dried meat (primarily beef, but also elk, turkey, and lamb), dried chokecherries, sunflower seeds, and clay. Fresh beef, chokecherries, and sunflower seeds all contain significant proportions of oleic acid (18:1n9). Fresh sunflower seeds and chokecherries, but not beef, also contain significant amounts of polyunsaturated acids such as C18:2 and C18:3. After 20 years of sitting on a laboratory shelf, exposed to air and light, lipid residues in the tools were extracted and analyzed via GC-MS. Analysis revealed that the lipid residues were highly oxidized. Most of the unsaturated fatty acids had disappeared and the dominant peaks were various diacids between 7 to 12 carbons in length (Buonasera 2013a).

Table 3. Relative percentages of fatty acids in Gila Cliff Dwellings samples and in an aged sunflower seed residue.

\begin{tabular}{|c|c|c|c|c|c|}
\hline \multirow[b]{2}{*}{ Fatty acids } & \multicolumn{5}{|c|}{ Samples } \\
\hline & $\begin{array}{l}\text { GNM 1-2 } \\
\text { Cupule }\end{array}$ & $\begin{array}{l}\text { GNM 1-3 } \\
\text { Control }\end{array}$ & $\begin{array}{c}\text { GNM 3-1 } \\
\text { Grinding surface }\end{array}$ & $\begin{array}{c}\text { GNM 3-2 } \\
\text { Control }\end{array}$ & Aged sunflower \\
\hline C8:0 & 1.0 & 0 & 0.1 & 0 & 1.0 \\
\hline C9:0 & 2.0 & 0 & 0.3 & 0 & 1.1 \\
\hline C10:0 & 1.3 & 0 & 0.2 & 0 & 0.4 \\
\hline C11:0 & 0.5 & 0 & 0.1 & 0 & 0 \\
\hline C12:0 & 2.5 & 0 & 0.3 & 5.9 & 1.1 \\
\hline C13:0 & 0.7 & 0 & 0.2 & 0 & 0 \\
\hline C14:0 & 5.0 & 2.4 & 0.9 & 9.3 & 1.4 \\
\hline C15:0 & 2.5 & 0 & 1.4 & 1.4 & 0.6 \\
\hline C16:1 & 3.0 & 0 & 0 & 0 & 0 \\
\hline C16:0 & 41.3 & 51.7 & 47.5 & 48.2 & 55.3 \\
\hline C17:0 & 1.9 & 0 & 1.8 & 2.7 & 0.9 \\
\hline C18:2 & 1.0 & 1.6 & 0 & 0 & 0 \\
\hline C18:1 & 4.6 & 0 & 0 & 4.1 & 2.0 \\
\hline C18:0 & 25.0 & 38.5 & 34.9 & 23.9 & 32.0 \\
\hline C20:1 & 0 & 0.2 & 0 & 0 & 2.0 \\
\hline C20:0 & 1.9 & 1.6 & 4.4 & 2.5 & 1.3 \\
\hline C21:0 & 0 & 4.2 & 0.4 & 0 & 0 \\
\hline C22:1 & 0 & 0 & 0 & 0 & 0 \\
\hline C22:0 & 5.9 & 0 & 5.7 & 2.0 & 2.7 \\
\hline C24:0 & 0 & 0 & 1.5 & 0 & 0.3 \\
\hline Total & 100 & 100 & 100 & 100 & 100 \\
\hline
\end{tabular}

Notes: (Buonasera 2013a).

Despite their advanced state of degradation, and having initially contained high amounts of oleic acid, neither the aged chokecherry nor the meat residue contained any dihydroxy fatty acids. The residue from sunflower seed grinding did contain a very small amount of 9, 10dihydroxy-octadecanoic acid, but only a single isomer was present. In the case of the experimentally aged sunflower seed residue, the precursor molecule may have been a naturally occurring epoxy fatty acid. Sunflower seeds are known to contain small amounts of cis-9, 10-epoxy-octadecanoic acid (Badami \& Patil 1981; Millan et al. 1983), which has been shown to degrade into a single dihydroxy fatty acid, threo-9, 10-dihydroxy-octadecanoic acid (Mikolajczak et al. 1968). 
A prior interpretation of the Gila Cliff Dwellings residues suggested (probably erroneously) that the presence of 9, 10-dihydroxy-octadecanoic acids in the grinding surface (GNM 3-1) could be indicative of sunflower seed processing (Buonasera 2013b). However, given the presence of two isomers in the Gila Cliff Dwellings grinding surface (see Figures 9, 10,11 , and 12) it seems more likely that these compounds formed from the degradation of C18:1n9, which is present in wide variety of sources.

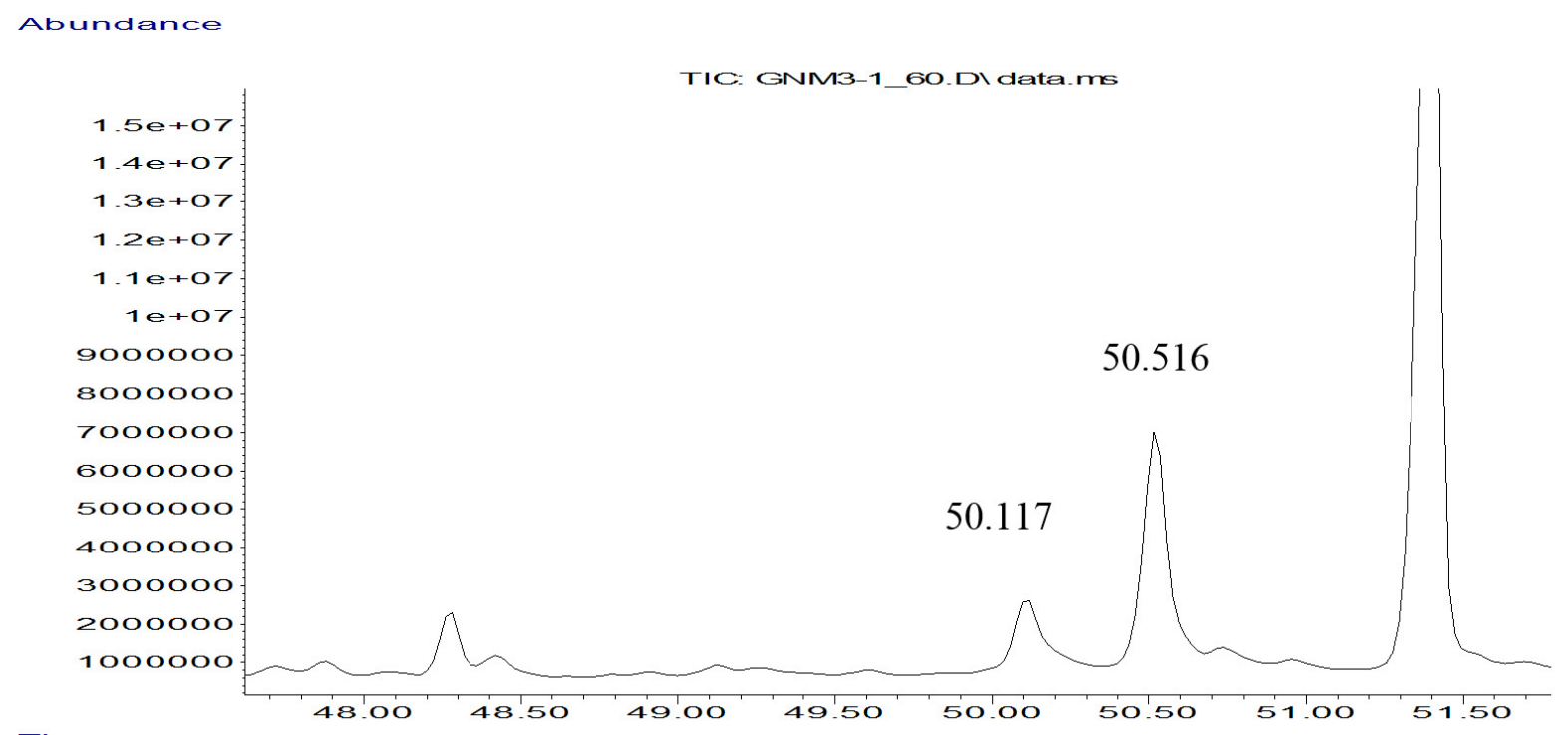

Figure 10. Partial TIC for the grinding surface core (GNM 3-1) showing peaks of interest at RT 50.117 and 50.516 .

Abundance

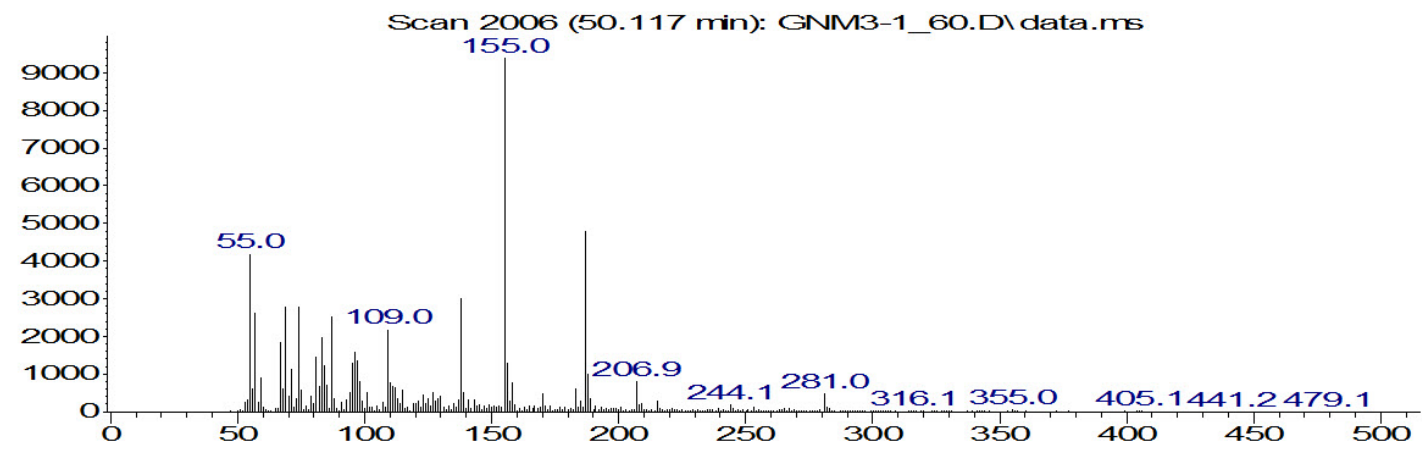

$m / z->$

Abundance

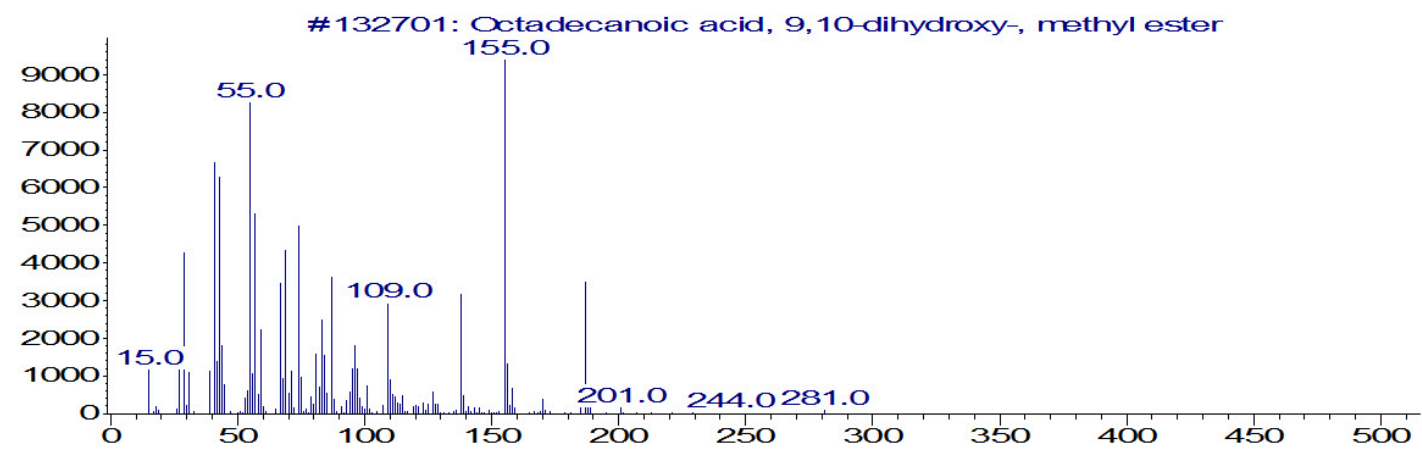

$\mathrm{m} / \mathrm{z}--^{-}$

Figure 11. Mass spectra for the grinding surface core (GNM 3-1) peak at 50.117 RT (upper image) and 9, 10dihydroxy-octadecanoic acid, methyl ester from the NIST mass spectral database 2.1(lower image). 


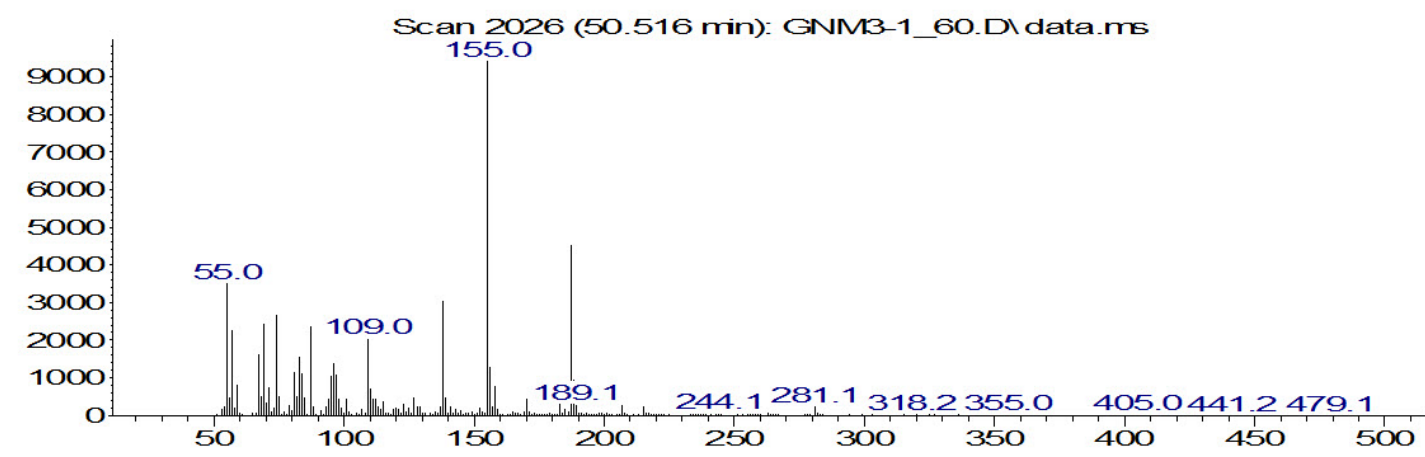

$\mathrm{m} / \mathrm{z--}>$
Abundance

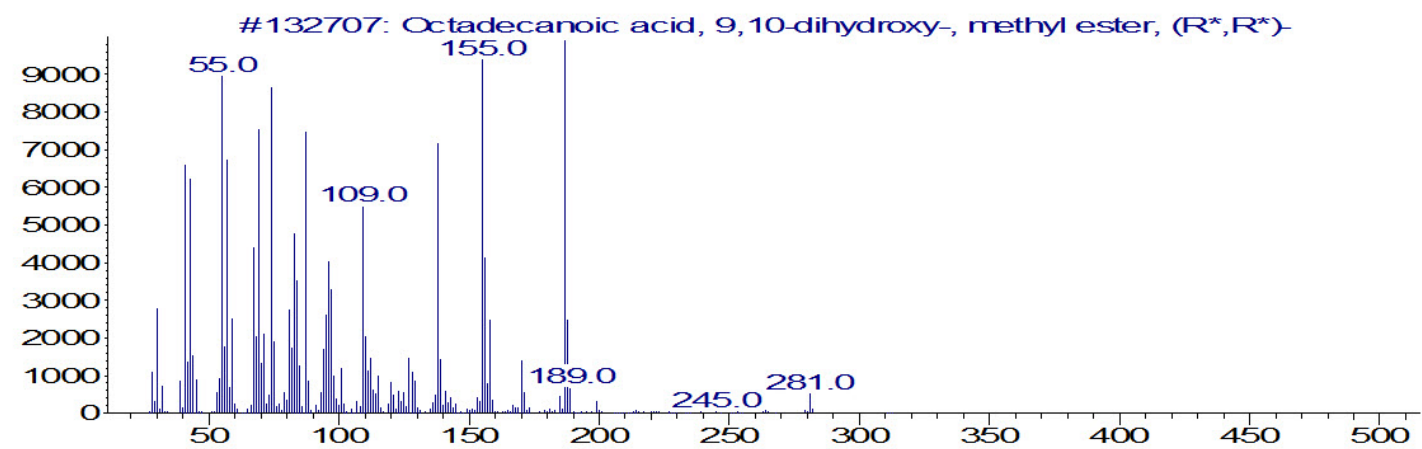

$m / z-->$

Figure 12. Mass spectra for the grinding surface core (GNM 3-1) peak at 50.516 RT (upper image) and 9, 10dihydroxy-octadecanoic acid, methyl ester, (R, R) from the NIST mass spectral database 2.1(lower image).

Ancient lipid residues in ceramics often contain a range of dihydroxy isomers, and experimental oxidation of C18:1n9 in heated ceramics has been shown to proceed through a pathway that results in a mixture of two 9, 10-dihydroxy-octadenanoic acid isomers (Hansel \& Evershed 2009). It has been suggested that high temperatures, expected to affect residues in cooking pots but not necessarily in grinding tools, may significantly increase the formation of dihydroxy acids from unsaturated fatty acids (Hansel \& Evershed 2009). If this is true, then the presence of 9, 10-hydroxy-octadecanoic acid isomers in the Gila Cliff Dwelling grinding surface could provide evidence for the use of processing techniques that included exposure to high temperatures. More research is needed on the formation of dihydroxy fatty acids in rock surfaces, but charring and roasting of seeds prior to hulling is well attested to ethnographically. Direct exposure to fire or hot coals was used to remove chaff and to roast a variety of seeds prior to grinding (Barrett 1952: 86; Fowler 1976), and to open green pinyon cones (Adams \& Huckell 1986: 263).

Considered together, the high lipid concentration, saturated fatty acid ratios, suite of diacids, dihydroxy fatty acids, and long chain fatty acids indicate that lipids in the milling surface are derived from processing a plant residue with a high oil content-very likely an oily seed or nut. Furthermore, those seeds or nuts may have been exposed to high temperatures during an earlier stage of processing. Candidates recovered from cave deposits include wild sunflower seeds (Helianthus annuus), pumpkin seeds (Curcurbita pepo L), walnuts (Jugulans major), acorns (Quercus sp.) and pinyon seeds (Pinus edulis) (Adams \& Huckell 1986).

Although maize kernels and cobs were the dominant plant remains recovered from the Gila Cliff Dwellings deposits, maize is an unlikely candidate for the bulk of the grinding surface residue. Maize is less oily than many wild seeds, and a considerable concentration of lipids was detected in this feature. More importantly, given the high overall concentration of 
lipids, n-dotriacontanol, a long chain wax alcohol biomarker for maize processing (Reber et al. 2004), was not detected in the extract. However, some contribution from maize cannot be ruled out as smaller contributions from maize could be masked by larger contributions from seeds with higher oil content. Future studies could employ compound specific $\delta^{13} \mathrm{C}$ analysis to help identify lipid residues from $\mathrm{C}_{3}$ or $\mathrm{C}_{4}$ plants, or potential mixtures of the two.

Finally, it is important to consider the amount of lipid recovered from the grinding surface in light of the potential for AMS dating of the fatty acids (Stott et al. 2001; Stott et al. 2003: Berstan et al. 2008). Depending on their age, residues in the grinding surface could hold different implications for past human uses of the caves at Gila Cliff Dwellings. If the residues date to approximately $\mathrm{AD} 1280$, they would highlight the importance of oily seed and nut resources in addition to farmed maize by Mogollon inhabitants at Gila Cliff Dwellings. If, on the other hand, they predate AD 500, the residues and the bedrock features they date would provide evidence for seed or nut processing as well as evidence for significant use and occupation of the locale by earlier groups of mobile hunter-gatherers.

\subsection{Cupule residue}

Although the lipid content in the cupule sample was seven times greater than the corresponding control sample, with $33 \mu \mathrm{g} \mathrm{g}^{-1}$ of fatty acids, it is still much lower than the amount recovered from the grinding surface. Some sort of contribution from a plant source seems likely, but there are reasons to doubt that the lipids from the cupule were derived from routine food processing. Considering the amount of smoke blackening in the caves, the black coating in the RMP-5 cupules, as well as the high relative amount of alkanes in the cupule core sample, it is possible that organics from condensed wood smoke could have accumulated in the sampled cupule. RMP-5 is located at the opening of the cave where heated air from interior fires would meet cooler exterior air, possibly causing some of the suspended particulates and vaporized organics to condense and be deposited on rock surfaces.

It is hypothesized that the concave surfaces may have acted to collect and concentrate smoke condensates introduced through years of exposure to smoke from cooking and heating fires in the caves. Contributions from wood smoke are also suspected because a smoky odour was detected by the author when this sample was drilled. Although, polycylic aromatic hydrocarbons (PAHs) were not identified in the extract, a complex array of monocylic aromatic hydrocarbon compounds (various substituted benzenes and phenols) was detected in this residue. Monocyclic aromatic hydrocarbons, like benzene and phenol derivatives, are also well-known components of wood smoke (Hawthorne et al. 1988; Naeher et al. 2007). It is possible that some of these monoaromatic compounds originate from plasticizers, especially since pthalates were detected in all samples; however, 3-5 times more monocyclic aromatic species were identified in the cupule residue verses either control residue. Further analysis of the black deposits, possibly using a different analytical strategy to separate and analyse more polar fractions of the extract, and also with the ability to analyse higher molecular weight polymers, could help to better assess the nature of the blackened deposits in cupules. It would also be helpful to compare future cupule samples to samples of black, sooty residues from the back and ceiling of the caves since these have a more certain origin as smoke deposits from past fires.

Aside from residue testing, the presence or absence of use-wear can be of considerable help in determining whether stone surfaces were used for food processing. In fact, the cupule sampled from RMP-5 (Figure 7) shows no evidence of levelling, striations, or other types of obvious wear that could indicate food processing. Instead, the surface appears rugged as if it was pecked but not used. In contrast, the grinding surface sampled from RMP-33 (Figure 6) shows striations and levelled surfaces common to milling tools. 
Due to their small size, tight clustering, and frequent occurrence on surfaces that would be impractical for food processing, cupules are usually not interpreted as having played a primary role in food grinding. Of course, this does not rule out the possibility that some organic substance was used in association with the cupules in the Gila Cliff Dwellings cave. Cupules are temporally and geographically widespread and may have had any number of different functions or meanings in different places or times (Parkman 1986; Gilreath 2007; Bednarik 2008). Several ethnographic accounts attribute their formation to fertility rituals, "increase rituals", or weather control (Barrett 1952: 385-387; see also references in Bednarik 2008: 73).

It is notable that some masonry walls at Gila Cliff Dwellings were constructed over cupule panels in the caves (this can be observed in Figures 3 and 4). The cupules in Figures 3 and 4 are both in Cave 5 and in close proximity to several Mogollon Red style pictographs, which Anderson et al. (1986: 57) suggest predate the masonry structures. It is possible that some or even most of the numerous cupule features date to earlier uses of the caves. With that in mind, it would be useful, once again, to know whether the mortars and grinding features date to archaic timeframes, or if they date to the later Mogollon occupation sequence. Changes in the uses and types of bedrock features may correspond to the evolving significance and use of the caves by different human groups through time.

\section{Conclusions}

Although the sample size is small, this study provides data on the functions of different types of bedrock features at Gila Cliff Dwellings. It also provides information that will be useful for planning future applications-whether those applications occur at Gila Cliff Dwellings, or at other sites with protected bedrock features. High amounts of fatty acids were recovered from a bedrock grinding surface inside the dripline of the caves at Gila Cliff Dwellings National Monument. Analysis of the TIC indicates that the grinding surface residue was probably derived from an oily seed or nut resource that may have been heated during processing. Several promising candidates recovered from cave deposits include wild sunflower seeds (Helianthus annuus), pumpkin seeds (Curcurbita pepo L), walnuts (Jugulans major), acorns (Quercus sp.) and pinyon seeds (Pinus edulis) (Adams \& Huckell 1986). A biomarker for maize was not detected in the surface residue, but some contribution from maize processing cannot be ruled out. Lower amounts of fatty acids were recovered from a small core sample removed from a blackened cupule. The blackened cupule residue had a relatively high alkane to fatty acid ratio, as well as a complex array of monocyclic aromatic hydrocarbons, supporting the possibility that some portion of the lipids in the cupule could have been deposited through years of exposure to wood smoke from heating and cooking fires within the caves.

Of particular interest for understanding past occupations of the caves is the high concentration of lipids recovered from the grinding feature. With this amount of preservation, it might be possible to use lipids to date the use of some features in the dry caves at Gila Cliff Dwellings National Monument. This could help assign the use of certain features either to earlier archaic populations, or to the later Mogollon occupation. Furthermore, although lipids in the grinding feature were highly oxidized, they retained some of the more water-soluble products of oxidation such as diacids, short chain fatty acids, and hydroxy fatty acids that can provide additional information on the composition of original source materials. It is notable that many of these products are absent from the solvent extractable lipid fraction of milling tool samples or pottery sherds recovered from open sites, probably because they are leached away by water movement through the soil medium (Regert et al. 1998; Colombini et al. 2005). 
Given that dry sheltered environments are known to provide good organic preservation, and bedrock is, in general, less permeable to water than soil, it seems likely that similarly large quantities of lipids, including more polar compounds arising from the oxidation of mono- and polyunsaturated fatty acids, might be preserved in other sheltered bedrock features. For these reasons, bedrock milling features in dry rockshelters may provide especially productive contexts in which to apply organic residue analysis and derive new data about resource use and processing in antiquity.

\section{Acknowledgments}

Thanks to National Park Service Ranger Kara Naber at Gila Cliff Dwellings National Monument for initiating this project. Kara was also instrumental in selecting areas to sample. I performed the laboratory work at the Institute for Integrated Research in Materials, Environment, and Society (IIRMES) at California State University, Long Beach during the summer of 2010. The research presented here was made possible through a NSF funded visiting researcher program at IIRMES (BCS-0917702), and I am grateful to H. Neff, R. Gossett, and IIRMES staff members for their assistance during my stay. Many thanks to P. Doyle for the map in Figure 1, and for inserting scale bars in photos. Finally, I thank J. Eerkens and two anonymous reviewers for reading and commenting on earlier drafts of this manuscript. This manuscript benefited substantially from their comments and criticisms. Any errors are my sole responsibility.

\section{References}

Adams, J.L. 1988, Use-wear analysis on manos and hide-processing stones. Journal of Field Archaeology, 15(3): 307-315. doi:10.2307/530311

Adams, K., \& Huckell, L. 1986, Plant remains. In: The Archaeology of Gila Cliff Dwellings, (Anderson, K. M., Fenner, G. J., Morris, D. P., Teague, G., \& McKusick, C., Eds.), Publications in Anthropology Vol. 36, Western Archeological Conservation Center, Tucson: p. 277-317.

Anderson, K.M., Fenner, G.J., Morris, D.P., Teague, G., \& McKusick, C., (Eds.), 1986, The Archaeology of Gila Cliff Dwellings, Publications in Anthropology Vol. 36, Western Archeological Conservation Center, Tucson, 363 p.

Badami, R.C., \& Patil, K.P. 1981, Structure and occurrence of unusual fatty acids in minor seed oils. Progress in Lipid Research, 19: 119-153. doi:10.1016/0163-7827(80)90002-8

Barrett, S.A. 1952, Material aspects of Pomo culture. Bulletin of the Museum of the City of Milwaukee, Vol. 20, Parts 1 and 2. North American Press, Milwaukee, 507 p.

Bednarik, R.G. 2008, Cupules. Rock Art Research, 25(1): 61-100.

Berstan, R., Stott, A.W., Minnitt, S., Bronk-Ramsey, C., Hedges, R.E.M., \& Evershed, R.P. 2008, Direct dating of pottery from its organic residues: New precision using compound specific carbon isotopes. Antiquity, 82(317): 702-713. doi:10.1017/s0003598x00097325

Birk, J.J., Teixeira, W.G., Neves, E.G., \& Glasser, B. 2011, Faeces Deposition on Amazonian Anthrosols as Assessed from 5B-stanols. Journal of Archaeological Science, 38(6): 1209-1220. doi:10.1016/j.jas.2010.12.015

Bull, I.D., Simpson, I.A., Dockrill, S.J., \& Evershed, R.P. 1999, Organic geochemical evidence for the origin of ancient anthropogenic soil deposits at Tofts Ness, Sanday, Orkney. Organic Geochemistry, 30: 535-556. doi:10.1016/S0146-6380(99)00020-0 
Buonasera, T.Y. 2005, Fatty acid analysis of prehistoric burned rocks: A case study from central California. Journal of Archaeological Science, 32(6): 957-965. doi:10.1016/j.jas.2005.01.012

Buonasera, T.Y. 2007, Investigating the presence of ancient absorbed organic residues in groundstone using GC/MS and other analytical techniques: A residue study of several prehistoric milling tools from central California. Journal of Archaeological Science, 34(9): 1379-1390. doi:10.1016/j.jas.2006.10.028

Buonasera, T.Y. 2013a, Extracting new information from old experiments: GC/MS analysis of lipid residues in aged experimental grinding tools. SAS Bulletin, 36(1): 2-7.

Buonasera, T.Y. 2013b, Lipid residues preserved in cupules and grinding features in dry caves at Gila Cliff Dwellings National Monument, New Mexico. In: Expanding Archaeological Approaches to Ground Stone: Modeling Manufacturing Costs, Analyzing Absorbed Organic Residues, and Exploring Social Dimensions of Milling Tools, (Buonasera, T.Y.), Doctor of Philosophy dissertation at the School of Anthropology, University of Arizona, Tucson: p. 65-101.

Buonasera, T.Y., Tremayne, A.H., Darwent, C. M., Eerkens, J.W., \& Mason, O.W. 2015, Lipid biomarkers and compound specific $\delta^{13} \mathrm{C}$ analysis indicate early development of a dual-economic system for the Arctic Small Tool tradition in northern Alaska. Journal of Archaeological Science, 61: 129-138. doi:10.1016/j.jas.2015.05.011

Burton, M. 2003, Gas chromatography/mass spectrometry analysis of organic residues in ceramic and ground stone artifacts from INY-1317 and INY-1991. In: Lacustrine Lifestyles Along Owens Lake: NRHP Evaluation of 15 Prehistoric Sites for the Olancha/Cartago Four-Lane Project, U.S. Route 395, Inyo County, California, (Byrd, B.F. \& Hale, M., Eds.), Report Prepared for California Department of Transportation, Central California Cultural Resources Branch, Encinitas: p. 515-535.

Colombini, M.P., Modugno, F., \& Ribechini, E. 2005, Organic mass spectrometry in archaeology: Evidence for Brassicaceae seed oil in Egyptian ceramic lamps. Journal of Mass Spectrometry, 40: 890-898. doi:10.1002/jms.865

Condamin, J.F., Formenti, M.O., Metais, M.M., \& Blond, P. 1976, The application of gas chromatography to the tracing of oil in ancient amphorae. Archaeometry, 18(2): 195201. doi:10.1111/j.1475-4754.1976.tb00160.x

Copley, M.S., Berstan, R., Dudd, S.N., Docherty, G., Mukherjee, A.J., Straker, V., Payne, S., \& Evershed, R.P. 2003, Direct chemical evidence for widespread dairying in prehistoric Britain. Proceedings of the National Academy of Sciences, 100(4): 1524-1529. doi:10.1073/pnas.0335955100

Craig, O.E., \& Collins, M.J. 2002, The removal of protein from mineral surfaces: implications for residue analysis of archaeological materials. Journal of Archaeological Science, 29: 1077-1082. doi:10.1006/jasc.2001.0757

Craig, O.E., Forster, M., Andersen, S.H., Koch, E., Crombé, P., Milner, N.J., Stern, B., Bailey, G.N., \& Heron, C.P. 2007, Molecular and isotopic demonstration of the processing of aquatic products in Northern European prehistoric pottery. Archaeometry, 49(1): 135-152. doi:10.1111/j.1475-4754.2007.00292.x 
Craig, O.E., Love, G.D., Isaksson, S., Taylor, G., \& Snape, C.E. 2004, Stable carbon isotopic characterisation of free and bound constituents of archaeological ceramic vessels released by solvent extraction, alkaline hydrolysis and catalytic hydropyrolysis. Journal of Analytical and Applied Pyrolysis, 71: 613-634. doi:10.1016/j.jaap.2003.09.001

Dubreuil, L., \& Grossman, L. 2009, Ochre and hide-working at a Natufian burial place. Antiquity, 83(322): 935-954. doi:10.1017/S0003598X00099269

Dubreuil, L., \& Savage, D. 2013, Ground stones: a synthesis of the use-wear approach. Journal of Archaeological Science, 48: 139-153. doi:10.1016/j.jas.2013.06.023

Dubreuil, L., Savage, D., Delgado-Raack, S., Plisson, H., Stephenson, B., \& de la Torre, I. 2015, Current analytical frameworks for studies of use-wear on ground stone tools. In: Use-Wear and Residue Analysis in Archaeology, (Marreios, J.M., Gibaja Bao, J.F., \& Ferreira, N., Eds.), Manuals in Archaeological Method, Theory, and Technique. Springer International, Switzerland, p. 105-157. doi:10.1007/978-3-319-08257-8_7

Dudd, S.N., \& Evershed, R.P. 1998, Direct demonstration of milk as an element of archaeological economies. Science, 282: 1478-1481. doi:10.1126/science.282.5393.1478

Duwe, S. 2011. The Prehispanic Tewa World: Space, Time, and Becoming in the Pueblo Southwest. Ph.D Dissertation at the School of Anthropology, University of Arizona, Tucson, $690 \mathrm{p}$.

Eerkens, J.W. 2005, GC-MS analysis of fatty acid ratios of archaeological potsherds from the western Great Basin of North America. Archaeometry, 47(1): 83-102. doi:10.1111/j.1475-4754.2005.00189.x

Eitam, D. 2009, Late Epipalaeolithic rock-cut installations and groundstone tools in the southern Levant. Paleorient, 35(1): 75-104. doi:10.3406/paleo.2009.5279

Evershed, R.P. 1993, Biomolecular archaeology and lipids. World Archaeology, 25(1): 74-93. doi:10.1080/00438243.1993.9980229

Evershed, R.P. 2008a, Experimental approaches to the interpretation of absorbed organic residues in archaeological ceramics. World Archaeology, 40(1): 26-47. doi:10.1080/00438240801889373

Evershed, R.P. 2008b, Organic residue analysis in archaeology: the archaeological biomarker revolution. Archaeometry, 50(6): 895-924. doi:10.1111/j.1475-4754.2008.00446.x

Evershed, R.P., Heron, C., Charters, S., \& Goad, L.J. 1992, The survival of food residues: new methods of analysis, interpretation and application. Proceedings of the British Academy, 77: 187-208. URL: http://www.britac.ac.uk/pubs/proc/files/77p187.pdf

Fowler, C.S. 1976, The processing of ricegrass by Great Basin Indians. Mentzelia, 2: 2-4.

Gilreath, A. 2007, Rock art in the golden state: pictographs, petroglyphs, portable and panoramic. In: California Prehistory: Colonization, Culture Change, and Complexity, (Jones, T.L., \& Klar, K.A., Eds.), Alta Mira Press, Lanham, Maryland: p. 273-290.

Gunstone, F. 1999, Fatty Acid and Lipid Chemistry. Aspen Publishers, Inc., Maryland, 252 p.

Hansel, F.A., Copley, M.S., Madureira, L.A.S., \& Evershed, R.P. 2004, Thermally produced $\omega$-(o-alkylphenyl) alkanoic acids provide evidence for the processing of marine products in archaeological pottery vessels. Tetrahedron Letters, 45: 2999-3002. doi:10.1016/j.tetlet.2004.01.111 
Hansel, F.A., \& Evershed, R.P. 2009, Formation of dihydroxy acids from z-monounsaturated alkenoic acids and their use as biomarkers for the processing of marine commodities in archaeological pottery vessels. Tetrahedron Letters, 50(40): 5562-5564. doi:10.1016/j.tetlet.2009.06.114

Hawthorne, S.B., Miller, D.J., Barkley, R.M., \& Krieger, M.S. 1988, Identification of methoxylated phenols as candidate tracers for anthropogenic wood smoke pollution. Environmental Science and Technology, 22(10): 1191-1196. doi:10.1021/es00175a011

Heron, C., \& Evershed, R.P. 1993, The analysis of organic residues, and the study of pottery use. Archaeological Method and Theory, 5: 247-284.

URL: http://www.jstor.org/stable/20170233

Heron, C., Nilsen, G., Stern, B., Craig, O., \& Nordby, C. 2010, Application of lipid biomarker analysis to evaluate the function of 'slab-lined pits' in arctic Norway. Journal of Archaeological Science, 37(9): 2188-2197. doi:10.1016/j.jas.2010.03.016

Hjulstrom, B., \& Isaksson, S. 2009, Identification of activity area signatures in a reconstructed Iron Age house by combining element and lipid analyses of sediments. Journal of Archaeological Science, 36(1): 174-183. doi:10.1016/j.jas.2008.08.005

Horsfall, G. 1987, Design theory and grinding stones. In: Lithic Studies among the Contemporary Highland Maya, (Hayden, B., Ed.), University of Arizona Press, Tucson: p. 332-377.

Jackson, T.L. 1991, Pounding acorn: women's production as social and economic focus. In: Engendering Archaeology: Women and Prehistory, (Gero, J. M., \& Conkey, M. W., Eds.), Blackwell, Cambridge: p. 301-324.

Kedrowski, B.L., Crass, B.A., Behm, J.A., Luetke, J.C., Nichols, A.L., Moreck, A.M., Holmes, C.E. 2009, GC/MS analysis of fatty acids from ancient hearth residues at the Swan Point archaeological site. Archaeometry, 51(1): 110-122. doi:10.1111/j.14754754.2008.00384.x

Lambert, S.J. 1990, Results of XRD Analysis of Some Cave Deposits at Gila Cliff Dwellings National Monument, Report on file at Gila Cliff Dwellings National Monument, Silver City, New Mexico, 4 p.

Leftwich, B.M. 2010, Set in Stone: Bedrock Mortars and Behavior in the North-Central Sierra Nevada. Ph.D Dissertation at the Department of Anthropology, University of California, Santa Barbara, 398 p.

McKusick, C.R. 1986, Faunal remains. In: The Archaeology of Gila Cliff Dwellings, (Anderson, K.M., Fenner, G.J., Morris, D.P., Teague, G., \& McKusick, C., Eds.), Publications in Anthropology 36, Western Archeological Conservation Center, Tucson: p. 245-272.

Mikolajczak, K.L., Freidinger, R.M., Smith, C.R., Wolff, J.R., \& Wolff, I.A. 1968, Oxygenated fatty acids of oil from sunflower seeds after prolonged storage. Lipids, 3(6): 489-494. doi:10.1007/BF02530891

Millan, F., Vioque, E., \& Maza, M.P. 1983, Study of the neutral lipids of sunflower meal and isolates. Journal of the American Oil Chemists Society, 60(7): 1321-1325. doi:10.1007/BF02702109 
Morgan, E.D., Titus, L., Small, R.J., \& Edwards, C. 1984, Gas chromatographic analysis of fatty material from a Thule Midden. Archaeometry, 26(1): 43-48. doi:10.1111/j.14754754.1984.tb00316.x

Nadel, D., Filin, S., Rosenberg, D., \& Miller, V. 2015, Prehistoric bedrock features: recent advances in 3D characterization and geometrical analyses. Journal of Archaeological Science, 53: 331-344. doi:10.1016/j.jas.2014.10.029

Nadel, D., \& Lengyel, G. 2009, Human-made bedrock holes (mortars and cupmarks) as a Late Naufian social phenomenon. Archaeology, Ethnology and Anthropology of Eurasia, 37(2): 37-48. doi:10.1016/j.aeae.2009.08.012

Naeher, L.P., Brauer, M., Lipsett, M., Zelikoff, J.T., Simpson, C.D., Koenig, J.Q., \& Smith, K.R. 2007. Woodsmoke health effects: a review. Inhalation Toxicology, 19(1): 67-106. doi:10.1080/08958370600985875

Namdar, D., Stacey, R., \& Simpson, S. 2009, First results on thermally induced porosity in chlorite cooking vessels from Merv (Turkmenistan) and implications for the formation and preservation of archaeological lipid residues. Journal of Archaeological Science, 36(11): 2507-2516. doi:10.1016/j.jas.2009.07.003

Nordby, L. 2011, The Architecture of Gila Cliff Dwellings. Report on file at Gila Cliff Dwellings National Monument, Silver City, New Mexico, 80 p.

Parkman, B.E. 1986, Cupule petroglyphs in the Diablo Range, California. Journal of California and Great Basin Anthropology, 8(2): 246-259.

Passi, S., Picardo, M., DeLuca, C., Nazarro-Porro, M., Rossi, L., \& Rotilio, G. 1993, Saturated dicarboxylic acids as products of unsaturated fatty acid oxidation. Biochimica et Biophysica Acta, 1168(2): 190-198. doi:10.1016/0005-2760(93)90124-R

Rafferty, S.M. 2002, Identification of nicotine by gas chromatography/mass spectroscopy analysis of smoking pipe residue. Journal of Archaeological Science, 29(8): 897-907. doi:10.1006/jasc.2001.0747

Rafferty, S.M. 2006, Evidence of early tobacco in northeastern North America? Journal of Archaeological Science, 33: 453-458. doi:10.1016/j.jas.2005.08.006

Reber, E.A., Dudd, S.N., van der Merwe, N.J., \& Evershed, R.P. 2004, Direct detection of maize in pottery residues via compound specific stable carbon isotope analysis. Antiquity, 78(301): 682-691. doi:10.1017/S0003598X00113316

Regert, M. 2011, Analytical strategies for discriminating archaeological fatty substances from animal origin. Mass Spectrometry Reviews, 30(2): 177-220. doi:10.1002/mas.20271

Regert, M., Bland, H.A., Dudd, S.N., van Bergen, P.F., \& Evershed, R.P. 1998, Free and bound fatty acid oxidation products in archaelogical vessels. Proceedings of the Royal Society, 265(1409): 2027-2032. doi:10.1098/rspb.1998.0536

Rosenberg, D. \& Nadel, D. 2014, The sounds of pounding: boulder mortars and their significance to Natufian burial customs. Current Anthropology 55(6): 1-29. doi:10.1086/679287

Schroth, A.B. 1996, An ethnographic review of grinding, pounding, pulverizing, and smoothing with stones. Pacific Coast Archaeological Society Quarterly, 32(4): 55-75. URL: http://www.pcas.org/vol32n4/324schr.pdf 
Simoneit, B.R.T., Rogge, W.F., Lang, Q., \& Jaffe, R. 2000, Molecular characterization of smoke from campfire burning of pine wood (Pinus elliottii). Chemosphere: Global Change Science, 2(1): 107-122. doi:10.1016/S1465-9972(99)00048-3

Sistiaga, A., Berna, F., Laursen, R., \& Goldberg, P. 2014, Steroidal biomarker analysis of a 14,000 years old putative human coprolite from Paisley Cave, Oregon. Journal of Archaeological Science, 41: 813-817. doi:10.1016/j.jas.2013.10.016

Standley, L.J., \& Simoneit, B.R.T. 1987, Characterization of extractable plant wax, resin, and thermally matured components in smoke particles from prescribed burns.

Environmental Science and Technology, 21: 163-169. doi:10.1021/es00156a006

Stott, A.W., Berstan, R., Evershed, R.P., Hedges, R.E.M, Bronk-Ramsey, C., \& Humm, M.J. 2001, Radiocarbon dating of single compounds isolated from pottery cooking vessel residues. Radiocarbon, 43(2A): 191-197.

URL: https://journals.uair.arizona.edu/index.php/radiocarbon/article/view/3954/

Stott, A.W., Berstan, R., Evershed, R.P., Bronk-Ramsey, C., Hedges, R.E.M., \& Humm, M.J. 2003, Direct dating of archaeological pottery by compound-specific 14C analysis of preserved lipids. Analytical Chemistry, 75(19): 5037-5045. doi:10.1021/ac020743y

Tushingham, S., Ardura, D., Eerkens, J.W., Palazoglu, M., \& Shahbaz, S. 2013, Huntergatherer tobacco smoking: earliest evidence from the Pacific Northwest Coast of North America. Journal of Archaeological Science, 40(2): 1397-1407.

doi:10.1016/j.jas.2012.09.019 